\title{
Complejidad y constructivismo en la nueva tradición de la arquitectura de la posguerra
}

\author{
Complexity and constructivism in the new tradition of post-war architecture \\ Complexidade e construtivismo na nova tradição da arquitetura do pós-guerra
}

Francisco Javier Fuentes-Farías

Universidad Michoacana de San Nicolás de Hidalgo, Michoacán (México)

Fuentes-Farías, F. I. (2019). Compleiddad y constructivismo en la nueva tradición de la arquitectura de la posguerra. Revista de Arquitectura (Bogotá), 2(l(), 34- 43. doi: http://dx.doi.org/10.14718/RevArq.2019.21.1.1496

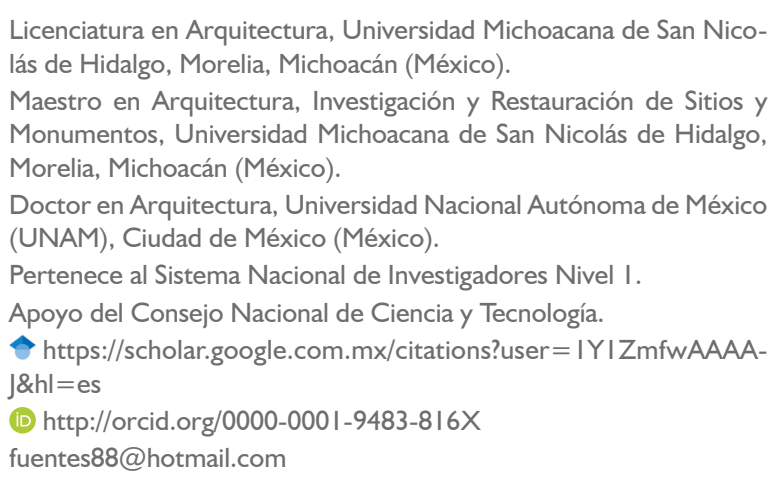

\section{Resumen}

Además de la arquitectura, otras disciplinas se han interesado por los aspectos intangibles, simbólicos o socioculturales del espacio edificado, buscando herramientas teóricas para su estudio. En este documento se cuestiona el alcance del Modernismo como un cambio de teorías y conceptos sobre el espacio y el tiempo, categorías que se comparan con otros conceptos clave referentes al significado que se da a los lugares habitados, y a la experiencia humana y corporal de los mismos. ¿Qué logros hay en el intento de expresar o manifestar las experiencias sensibles, emocionales, subjetivas y simbólicas del espacio urbano y arquitectónico? Se observan concepciones referentes a la vida subjetiva o mental de las personas en su interacción con el espacio urbano y arquitectónico, tales como: habitar, imaginarios, espacialidad, significado, etc., que pueden ser examinados como procesos cognitivos, según distintas corrientes en arquitectura, que integran neurociencias, ciencias cognitivas y fenomenología, entre otras, desde una visión constructivista, distinta al dualismo cartesiano.

Palabras clave: movimiento moderno; paisaje cultural; representación social; simbolismo; teoría arquitectónica.

\begin{abstract}
In addition to architecture, other disciplines have been interested in the intangible, symbolic, or socio-cultural aspects of built space, looking for theoretical tools for their study. This paper questions the scope of modernism as a change of theories and concepts about space and time, categories that are compared with other key concepts regarding the meaning given to inhabited places, as well as human and corporal experiences in them. What are the achievements in attempting to express or manifest sensitive, emotional, subjective, and symbolic experiences in urban and architectural spaces? The paper identifies concepts referring to the subjective or mental life of people in their interaction with urban and architectural spaces, such as the act of inhabiting, imaginaries, spatiality, meaning, etc., which can be examined as cognitive processes, according to different currents in architecture, which integrate neurosciences, cognitive sciences, and phenomenology, among others, from a constructivist perspective, different from Cartesian dualism.
\end{abstract}

Keywords: Modern movement; cultural landscape; social representation; symbolism; architectural theory;

\section{Resumo}

Além da arquitetura, outras disciplinas têm se interessado pelos aspectos intangíveis, simbólicos ou socioculturais do espaço edificado, buscando ferramentas teóricas para seu estudo. Neste documento, questiona-se o alcance do Modernismo como uma mudança de teorias e conceitos sobre o espaço e o tempo, categorias que são comparadas com outros conceitos-chave referentes ao significado que se dá aos lugares habitados e à experiência humana e corporal destes. Quais conquistas há na tentativa de expressar ou manifestar as experiências sensíveis, emocionais, subjetivas e simbólicas do espaço urbano e arquitetônico? Foram observadas concepções referentes à vida subjetiva ou mental das pessoas em sua interação com o espaço urbano e arquitetônico, tais como: habitar, imaginários, espacialidade, significado etc., que podem ser examinados como processos cognitivos, segundo diferentes correntes em arquitetura, que integram neurociências, ciências cognitivas e fenomenologia, entre outras, a partir de uma visão construtivista, distinta do dualismo cartesiano.

Palavras-chave: movimento moderno; paisagem cultural; representação social; simbolismo; teoria arquitetônica. 


\section{Introducción}

Como resultado de una línea de investigación desarrollada a partir de una tesis doctoral sobre el tema de paisajes culturales, en la que uno de los problemas principales se presenta a niveles metodológico y epistemológico, referente a cómo examinar las experiencias subjetivas, mentales o emocionales (recuerdos, creencias, costumbres, identidad, cultura, etc.) de las personas en su relación con el espacio construido (Fuentes, 2008; 2011, p. 20; 2017), el autor de este trabajo ha planteado en anteriores escritos un enfoque interdisciplinar y una crítica al dualismo cartesiano y al empirismo científico, enfoque basado en buena medida en la epistemología constructivista desarrollada por Piaget (García, 2013; Fuentes, 2008, 2011, 2017, 2018). En dichos trabajos se revisaron distintas corrientes de investigación tanto en ciencias sociales, geografía cultural y urbanismo, como en epistemología y crítica de la arquitectura, las cuales coinciden al señalar que las experiencias subjetivas de las personas requieren de un enfoque interdisciplinar y de una base teórica que incluya los paradigmas de la complejidad, la hermenéutica y la fenomenología.

La dimensión simbólica manifestada mediante las formas y los estilos arquitectónicos, y su utilidad social, presenta una problemática acerca del estatuto epistémico y conceptual de las experiencias subjetivas vinculadas al espacio construido, tales como la naturaleza de la belleza o el deleite de las formas arquitectónicas, o las interacciones sociales y simbólicas a partir de la utilidad o función social de tal espacio.

Si Giedion (2009) consideraba la arquitectura moderna como una nueva tradición tendiente a zanjar la brecha entre pensamiento y sentimiento, ¿qué se ha logrado, y cuáles han sido los principales cambios? No se ven respuestas sencillas, por lo cual conviene ceñirse a ciertos puntos principales, por lo que es necesario, en primer término, acordar qué tipo o modo de conocimiento podemos obtener acerca de la vida subjetiva de los demás, pues la complejidad de todo tipo de relaciones en el espacio arquitectónico y urbano -sean éticas, estéticas, sociales, político-económicas e ideológicas- hace que dicho espacio, en su concepción formal, remita siempre a una noción del mundo y del tiempo, del sujeto y del objeto (Montaner, 2013, p. 9).

Durante el siglo pasado cambió la manera de entender la arquitectura con respecto al sistema clásico; surgió así una "nueva tradición", una nueva concepción del espacio que se difundió en diversas corrientes estilísticas y teóricas (Jencks, 2011, pp. 48-49; Giedion, 2009), y señaló la importancia de la dimensión significante de las formas urbano-arquitectónicas, y la relación entre las partes y el todo construido, entre otros temas importan- tes. En la historia de la arquitectura se habla de un "asalto continuo e incesante a aquello que se creía que eran las persistencias de la arquitectura: sujeto y objeto, figura y fondo, sólido y vacío, y las relaciones de la parte con el todo" (Eisenmann, 2011, p. 16).

En la metodología se plantea que las experiencias subjetivas a las cuales hacen referencia conceptos como emoción, sentimiento, etc., pueden entenderse como procesos cognitivos, y estudiarse a partir de una perspectiva interdisciplinar desde una base teórica distinta al empirismo científico, la cual se puede resumir como una epistemología constructivista. En esta concepción del conocimiento, por ejemplo, en la geografía constructivista o en la teoría social (Lindón, 2012), se asumen las disciplinas de la fenomenología y la hermenéutica desde una perspectiva comprensiva e interpretativa, más que explicativa o analítica, y, al mismo tiempo, se cuestiona la concepción dualista del conocimiento en la óptica cartesiana, basada en el método científico.

En el desarrollo del tema se muestra cómo distintas disciplinas del área de la filosofía y las humanidades ayudan a plantear la cuestión de las experiencias mentales o subjetivas de los demás, y cómo los modelos de la fenomenología y la semiótica son retomados o integrados en estudios interdisciplinares, como en los ejemplos citados.

La idea de que la arquitectura (el espacio construido) puede entenderse como un lenguaje, como escritura, que identifica al periodo posmodernista y puntualiza problemáticas como la del significado de las formas arquitectónicas, y del contexto o paisaje que circunda a dichas formas. Así tenemos distintas tendencias en diseño urbano y arquitectónico surgidas del Modernismo de la posguerra, que se acercan a otras propuestas filosóficas como la semiótica pragmatista de Peirce, a la fenomenología de Bachelard y Merleau-Ponty, al existencialismo de Heidegger, al deconstructivismo de Derrida, y también al modelo de la complejidad (teoría de sistemas, epistemología genética) (Montaner, 2013; 2015, p. 7; Pallasmaa, 2016, 2011; Otero-Pailos, 2010; Mallgrave, 2013; Mallgrave y Goodman, 2011; Pérez-Gómez, 2016; Jencks, 2011; Alexander, 2003; Davies, 2011, pp. 130,133; López, 2014; 2015).

Como resultado, se verá por qué es tan importante comprender los alcances del movimiento moderno y su relación con otros campos de la sociedad, la cultura y la historia de las ideas, que en conjunto fundamentan el quehacer arquitectónico. Se verá también que hoy día continúa vigente la necesidad de explicar y comprender la dimensión simbólica y significante del espacio habitado, urbano y arquitectónico, que subyace tanto desde el momento del diseño como en las relaciones sociales e interacciones simbólicas y experienciales de quienes viven ahí. 
Se confirma que una manera de entender los alcances de la nueva tradición en arquitectura es mediante una crítica o rebasamiento conceptual que permita una integración disciplinar para explicar la relación entre las personas y el espacio edificado, y entre sentimiento y pensamiento, entre razón y emoción, tomando en cuenta los paradigmas de la complejidad y la teoría de sistemas, el constructivismo, la fenomenología y la hermenéutica.

Se concluirá señalando la pertinencia de distintos enfoques constructivistas en geografía cultural y en el pensamiento urbanístico contemporáneo, como también la necesidad de una integración disciplinar que disponga de herramientas conceptuales y de un instrumental epistémico apropiado ante el complejo desarrollo del espacio urbano y arquitectónico de la actualidad. Como ejemplos de ello se mencionan las neurociencias, la neurofenomenología y las ciencias cognitivas desde una perspectiva fenomenológica, así como la psicolingüística de George Lakoff, etc. (Pérez-Gómez, 2016, pp.149-163; Otero-Pailos, 2010, pp. 251-253; Mallgrave, 2013, pp. 55-57; Pallasmaa, 2011; 2016, p. 114; Montaner, 2015, p. 52).

\section{Metodología}

Buscando respuestas acerca de cómo es posible examinar o, mejor dicho, comprender e interpretar la idea de allanar la brecha entre razón y emoción, entre pensamiento y sentimiento, propuesta por la "nueva tradición" en arquitectura, según lo dicho arriba, se plantea aquí una comparación de distintas ideas y conceptos clave referentes a los procesos cognitivos involucrados en la relación entre la gente y el espacio arquitectónico. Por ejemplo, el concepto de habitar se ha entendido como el proceso de dar sentido o significado al espacio construido, al espacio que la gente vive cotidianamente, al espacio público (Montaner, 2013, pp. 20, 22).

Así, en áreas como la geografía constructivista, el pensamiento urbanístico, los estudios urbanos o la teoría social, el concepto de habitar podría entenderse dentro de un proceso de cambio de teorías, en congruencia con la idea de conocimiento como una construcción en diversos planos: teórico, metodológico, y de los procesos de realidad social. Lo que podríamos llamar hechos sociales o simbólicos no parecen accesibles a una metodología científica en el sentido del llamado empirismo científico o dualismo cartesiano, como veremos en los resultados, por lo cual es importante señalar que una epistemología constructivista procede estableciendo niveles de análisis en concordancia con niveles de realidad. En tal sentido, este trabajo se asume como interpretativo y comparativo, y como una reflexión del autor.
Un primer paso es precisamente la definición conceptual que toda base teórica requiere. Aquí se ha puesto como punto principal la cuestión de qué tipo de conocimiento podemos obtener acerca de las emociones o la vida subjetiva de los demás, precisando que una cosa es conocer por medio de los procedimientos de una ciencia empírica, y otra es comprender o interpretar la realidad que viven otras personas. A ello se puede referir como un cambio de teorías.

Como ejemplos, además de los citados en este escrito, se tienen ciertas líneas como la Teoría social contemporánea y la Geografía humana en sus vertientes inglesa y francesa (Lindón, 2014, pp. 63-65; 2012, p.611), donde se trabaja, por ejemplo, el concepto de "espacio vivido" proveniente de la fenomenología, como se señaló, como también el concepto clave de la Unesco de "vida cotidiana" (Fuentes, 2015, pp. 62-63).

Como se mencionó al principio, buscando explicaciones a la relación entre el espacio construido y quienes lo habitan, se revisa el periodo histórico de la posguerra, a mitad del siglo $X X$, durante el florecimiento de la llamada nueva tradición en arquitectura, cuya propuesta era "cerrar la brecha" entre razón y emoción, pensamiento y sentimiento. Ante la pregunta acerca de los resultados de la "nueva tradición", se revisan algunas propuestas teóricas que abordan los aspectos simbólico y subjetivo de aquello a lo cual se hace referencia al decir emoción, o sentimiento, por ejemplo, y así entender la influencia de los paradigmas emergentes de la complejidad, el constructivismo, la fenomenología y la hermenéutica (Mallgrave, 2013, p. 9; Mallgrave y Goodman, 2011, pp. 18-19, 40, 123, 141; Eisenman, 2011, pp. 134-135; Davies, 2011, pp. 25, $37,38,40)$.

Además, ya que uno de los aspectos relevantes de estas corrientes o propuestas de investigación se refiere a la idea de conocimiento, se tiene una integración disciplinar o una interdisciplina, según lo asentado en la epistemología constructivista de Piaget (García, 2013). También, en la medida que los aspectos de la realidad que se quiere examinar son igualmente complejos, y sujetándose al tema de estudio propuesto aquí, parece importante profundizar en lo que se entiende como subjetividad, mente o vida interior de las personas. Ello permitiría una mejor comprensión del sentido, de lo que significa, "cerrar la brecha" entre razón y emoción.

\section{Resultados}

\section{Los alcances de la nueva tradición}

Como una respuesta ante los grandes cambios marcados por las dos guerras mundiales, el movimiento moderno en arquitectura emerge con un gran desarrollo de la ciencia y una fe ciega en la tecnología, y con la creencia de que la Modernidad podrá reparar la devastación física y moral 


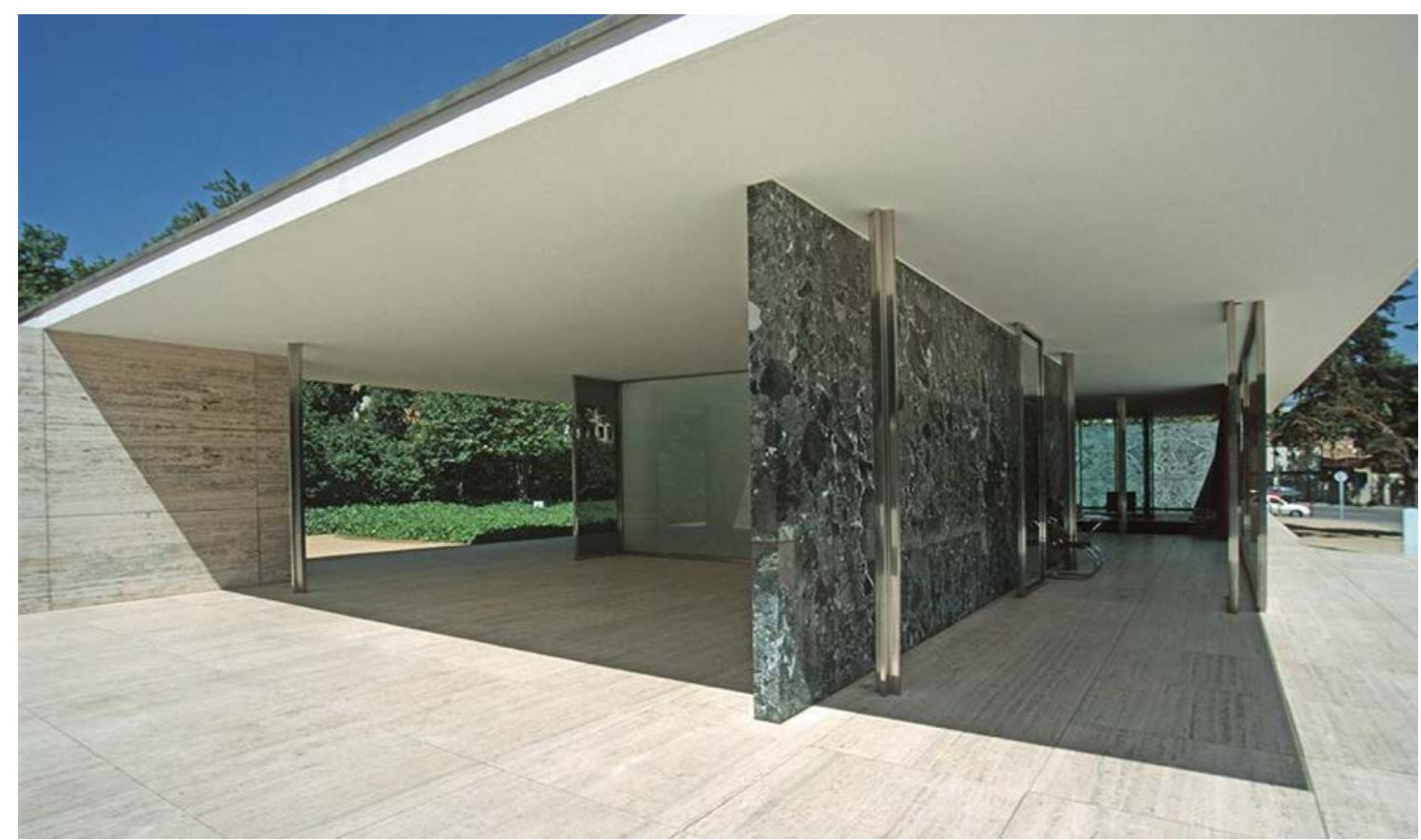

¿ Figura 1. Pabellón de Barcelona. Van der Rohe, 1929. Adentro y afuera, conceptos que el Modernismo cambió Fuente: Schaefer (1999). CC BY-SA 3.0 del planeta (Mallgrave y Goodman, 2011, p. 1). Desde el fin de la Segunda Guerra Mundial, hasta mediados de los años sesenta, la idea de que la humanidad podría destruirse a sí misma impulsó una frenética necesidad de fundar nuevas ciudades "como no había ocurrido desde el siglo XIII" (Giedion, 2009, p.18), lo cual también propició un nuevo consenso acerca de que era necesario preservar ciertos valores que parecían perderse: "la escala humana, los derechos del individuo, y la seguridad más rudimentaria del movimiento dentro de la ciudad" (p. 18). Sin embargo, "la arquitectura moderna ha degenerado en un juego de efectos neoexpresionistas o bien en un rígido formalismo neorracional" (Norberg-Schulz, 2005, p. 43), debido a lo cual Norberg-Schulz veía en la fenomenología de Husserl la manera de crear ese nuevo lugar, de cerrar la brecha entre pensamiento y sentimiento, pues "el movimiento moderno se quedó varado en el punto muerto de lo científico" (p. 44).

Entre los alcances de la nueva tradición (sobre todo a partir del posmodernismo, entre las décadas de 1960 a 1980) se podría mencionar una síntesis entre ciencias y filosofía (Jencks, 2011, p. 40; Montaner, 2014, pp.13-16; 2010, pp. 15, 32, 72; Mallgrave, 2013, pp. 8, 9; Davies, 2011, pp. 6, 8; Otero-Pailos, 2010, pp. 9, 10, 12; Mallgrave y Goodman, 2011, pp. 39, 123, 129; Pallasmaa, 2016, p. 115) para plantear nuevas concepciones del espacio-tiempo, pero también del sujeto-objeto, es decir, del objeto arquitectónico y las personas que lo habitan, así como de las nociones fundamentales de la obra construida tales como forma y función, forma y fondo, sólido y vacío, etc. Se puede decir que todos estos conceptos o categorías se interrelacionan entre sí, de modo que no se podría acercar a la vida subjetiva de las personas sin antes aclarar las mencionadas nociones fundamentales de la arquitectura. En tal sentido, habitar el espacio implica darle sentido, significado, lo cual le otorga a dicho espacio un estatuto ontológico.
Se verá en seguida qué tipo de herramientas epistemológicas pueden apoyar en la comprensión de la subjetividad humana, y, al mismo tiempo, hacer una distinción entre la idea de conocimiento en el sentido del dualismo cartesiano y el conocimiento desde el punto de vista constructivista. Según Pérez-Gómez (2016, pp. 141-142), mientras que la epistemología cartesiana europea excluyó de su territorio a los sentimientos o emociones, se tiene una primera aproximación al enfoque de la experiencia sensible o fenomenológica, esto es, corporizada, de nuestro "sentimiento de existencia", la del filósofo francés Maine de Biran a principios del siglo XIX.

\section{El instrumental de las humanidades}

Una manera de cerrar la brecha entre pensamiento y sentimiento, según Norberg-Schulz (2005, p. 248; Fuentes, 2018, p.117) era la creación de un nuevo lugar, y con tal propósito subraya la importancia del habitar, es decir, de dar significado a las sensaciones y experiencias perceptuales del cuerpo, por ejemplo, el bienestar, ante el espacio construido. Por ello resulta necesario recordar la obra de autores que, como Husserl, Heidegger, Bachelard y Merleau-Ponty, entre otros, dieron una idea sobre la problemática acerca de cómo se experimenta o percibe el mundo circundante, hecho de objetos, luz y sombras, adentro y afuera, arriba y abajo, y también de relaciones sociales y simbólicas (Figura 1).

Heiddegger (retomado ampliamente por Norberg-Schulz, 2005, p. 248; Pallasmaa, 2011, pp. 104, 123; Davies, 2011, pp. 68, 90; Otero-Pailos, 2010, pp. 18, 19, 146, 147; Pérez-Gómez, 2016; Mallgrave, 2013, pp. 61, 145, 146) indicaba que la construcción solo es posible cuando "somos capaces de habitar", es decir, cuando le damos significado a los lugares como un espacio destinado a asentarnos (Heiddegger, 1997, p. 105), pero al mismo tiempo, lo hacemos como una delimitación del espacio-tiempo en un sentido ontológico y cognitivo, es decir, como categorización 
y ordenamiento de lo existente (Norberg-Schulz, 2005, pp. 22, 33,45). Por ello, Norberg-Schulz sostiene lo dicho por el filósofo alemán, para quien: "orientación e identificación significan habitar" (Heiddegger, 1997, p. 250).

En 1951, Heidegger pronuncia una conferencia bajo el título: "Construir, habitar, pensar", que tendrá hondas repercusiones en el pensamiento contemporáneo, sobre todo en aquellas disciplinas interesadas en la relación entre las personas y el espacio construido, urbano, social y cultural. Para Heidegger (1997, p. 116), habitar es una práctica, una experiencia constante. Se existe aquí y ahora mediante el habitar, y de ese modo es posible construir. Durante las décadas de los sesenta y setenta, en el discurso arquitectónico sobre la experiencia de habitar fue clave la palabra "lugar" (Otero-Pailos, 2010, pp. xiv, 19; Pallasmaa, 2016, p. 10), ampliamente usada para denotar la sensibilidad posmoderna al espacio en el sentido heidegeriano.

Es decir, se trata de un proceso cognitivo que resulta de la experiencia, orientada corporalmente, del espacio. Así, la arquitectura (el espacio construido) no consiste solamente en una representación de algo más (p. e., las intenciones o el cometido de quien construye), sino en "visualizar un modo distinto de estar entre la tierra y el cielo" (Norberg-Schulz, 2005, p. 32). Existir entre el cielo y la tierra es una frase más bien metafórica que habrá que interpretar adecuadamente, y que de antemano observamos desde un punto de vista ontológico, en el sentido que ha hecho notar Norberg-Schulz (p. 33) al recordar que "en el pasado, las concepciones del espacio y la forma estaban unificadas en imágenes", imágenes tales como "el arco, la columna, el hastial, la torre, la pirámide y la rotonda".

Otro concepto importante acuñado desde las humanidades y las ciencias sociales, la espacialidad, se puede observar en el modo en que la obra arquitectónica se erige sobre el terreno, cómo se eleva hacia el cielo y se extiende en el horizonte, y cómo se abre y se cierra hacia el mundo circundante (Norberg-Schulz, 2005, p. 32). Norberg-Schulz enfatiza la experiencia perceptual en tanto relación del ser humano con su ambiente, en términos de la construcción gradual de una conciencia de espacio, la cual define un marco general de referencia, un lugar constituido de imágenes, mismas que le dan a los lugares un determinado carácter, esto es, el "espíritu del lugar", gracias a lo cual "la obra arquitectónica puede actuar como una verdadera imago mundi" (pp. 33, 34, 234, 240, 250; Pallasmaa, 2011, pp. 10, 14, 32).

En un mundo de interacción y cambio, la orientación y la identificación significan habitar. Según Norberg-Schulz (2005, pp. 249, 250), "la recuperación del lugar como un 'aquí' concreto que concentra un mundo presupone una actitud fenomenológica". En el espacio construido se revela la "espacialidad del mundo", y la arquitectura ofrece un espacio "que permite que la vida ocurra"; en ese cometido, el lugar construido, el edificio, dice Norberg-Schulz, manifiesta un modo de vida (p. 36).

También Pallasmaa (2011, pp. 97, 104) considera la preponderancia de la corporalidad y la experiencia perceptual o sensible, al señalar que las imágenes primordiales de la arquitectura son, en orden de su emergencia ontológica, el piso, el techo, los muros, las puertas, las ventanas, etc., puesto que la arquitectura nace al establecer una superficie horizontal, y unos límites entre el adentro y el afuera que influyen directamente en la experiencia sensible del bienestar que brinda el espacio construido (p. 129; Alexander, 1981, p. 111).

\section{El constructivismo y la teoría de sistemas}

Según Jencks (2011), en las nuevas ciencias y arquitecturas, la idea fundamental se relaciona con la retroalimentación, con el cambio que se autoorganiza, "que la computadora está bien adaptada para representar". Además, fue consolidándose la idea de un universo "radicalmente interconectado y creativo", como una entidad que repentinamente salta (emerge) a nuevos niveles de organización (p. 13).

Se dispone de varias vías para acceder a una comprensión básica del modelo constructivista o de la epistemología genética de Piaget (García, 2013; López, 2015, pp. 18, 19; 2014, p. 15; Montaner, 2013), y una de ellas es la idea de un modo de pensamiento no lineal. Dicho modo de pensamiento ya se había dado a mitad del siglo XX; entre otros ejemplos tenemos el de Buckminster Fuller, quien daba relevancia a las relaciones ecológicas del espacio construido, comparando al planeta con una nave espacial y, por lo tanto, señalando la importancia de la planificación (Mallgrave y Goodman, 2011, pp. 4-5).

El constructivismo, si bien posee diversos sentidos (que aquí observamos en tres niveles: teoría, método y realidad), es bien conocido por las colaboraciones de Edgar Morin y Jean Piaget (García, 2008, pp. 15, 31, 34; López, 2015, pp. 18, 19, 41; 2014; Montaner, 2010, pp. 63, 79), cuyas obras se mantienen vigentes en la medida de su influencia en filosofía, humanidades y ciencias.

Volviendo a nuestro tema, lo que muestra el movimiento de la nueva tradición en arquitectura es una elucidación de conceptos que permite distintas interpretaciones relacionadas con el arte, la arquitectura, el urbanismo, o la geografía y las ciencias sociales, en la medida que, según Montaner (2013, p. 9), si abordar el tiempo y del sujeto es tarea de filósofos, antropólogos, sociólogos y psicólogos, entonces, al mismo tiempo que se va a analizar la complejidad formal y estructural de las obras arquitectónicas deben contemplarse también sus relaciones con el contexto paisajístico, urbano, socio-político y simbólico. 


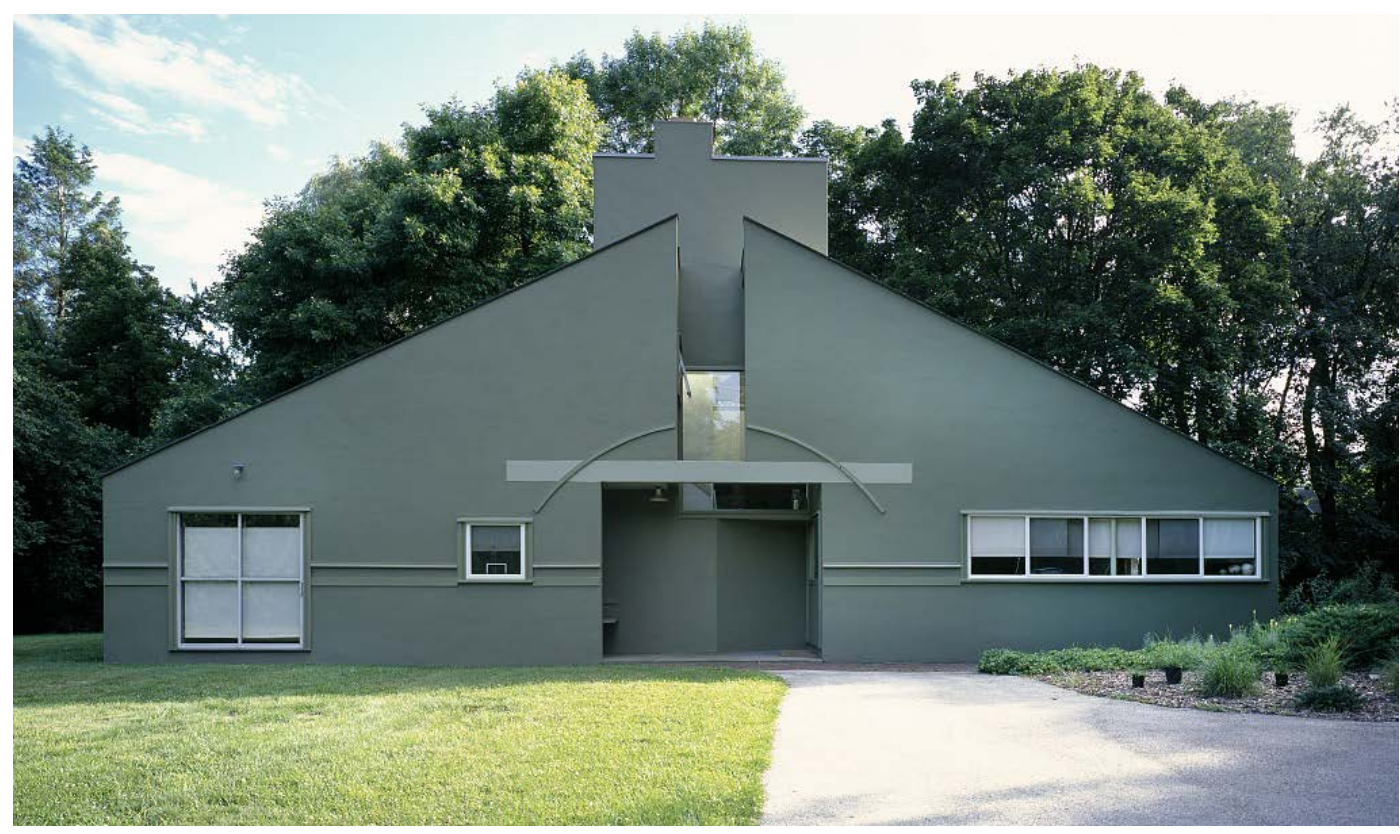

Figura 2. Casa Vanna, 1964, R. Venturi. Una crítica a la relación clásica de la parte con el todo.

Fuente: Highsmith C. M. Archive (1989). Dominio público $\mathrm{CO}$.

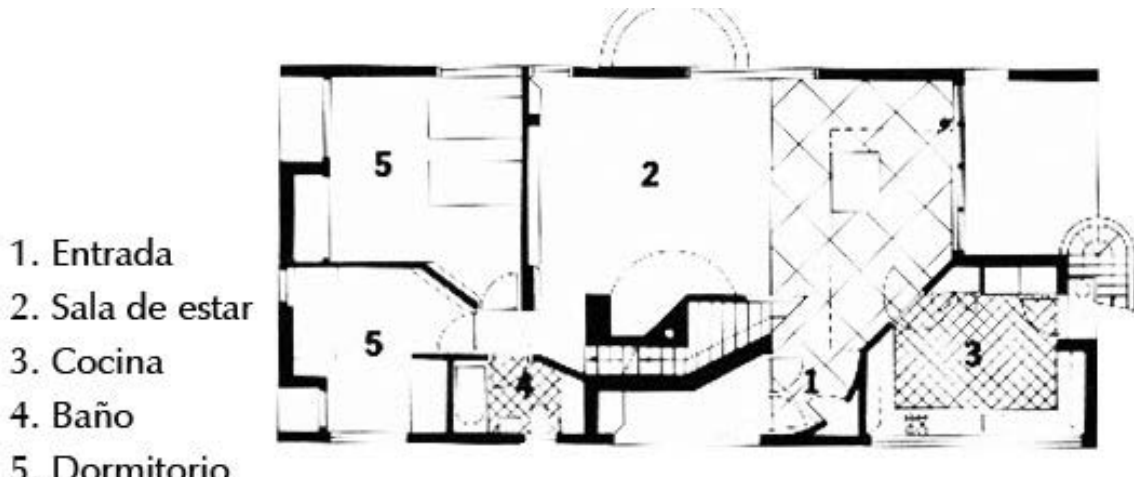

Planta baja \&igura 3. Casa Vanna: complejidad y contradicción

Fuente: Pauortizsat (2013). CC BY-SA 3.0
Como se ha visto, con el posmodernismo cobra relevancia el contexto en que se erige la obra arquitectónica, el significado de las formas y los lugares, y la idea de que el espacio arquitectónico puede entenderse como lenguaje (Mallgrave y Goodman, 2011, pp. 38-40). Al respecto, Venturi (1966) es uno de los pioneros al introducir el tema del significado en arquitectura, y materializarlo en una obra construida, pero no en el sentido en que se manejó en el estructuralismo, en el enfoque analítico sobre el lenguaje, y el posestructuralismo europeos (Eisenmann, 2011, p. 131), sino al poner de relieve la contradicción entre una afirmación y negación simultánea entre "las partes y el todo" arquitectónico (pp. 134-135) (Figuras 2 y 3). Y esto es así porque con el avance de la ciencia y la tecnología, en particular en el campo de la física, comenzó a revelarse también un universo básicamente creativo, abierto, dinámico, sorprendente y activo, no pasivo (Jencks, 2003a, p. 8), y en esta complejidad tenemos básicamente el problema de comprender el sentido de las experiencias fenoménicas que Jencks menciona como "el significado estético y espiritual de la naturaleza" (2003b, p. 43), mismo que el movimiento moderno había ignorado.

Si el movimiento moderno se condujo hacia la idea de un universo ordenado según las leyes newtonianas, la nueva comprensión de la realidad implicó un giro ante términos como determinismo, mecanicismo, reduccionismo y materialismo, característicos de la visión moderna, y la difusión de nuevos conceptos tales como: emergencia, autoorganización, evolución (diversificación) y cosmogénesis (Jencks, 2003a, p. 124).

También se habla de la obra de Jencks, El lenguaje de la arquitectura posmoderna (1977) como el tercer paso hacia una tradición de interpretaciones semiológica de las formas arquitectónicas: el primero fue El lenguaje clásico de la arquitectura (1963), de John Summerson, y el segundo El Lenguaje moderno de la arquitectura (1973), de Bruno Zevi (Montaner, 2010, pp. 80-81). Por otro lado, la idea de totalidad aquí empleada es la que ya Alexander (2003, p. 6; 1981, pp.136$137,374)$ viene señalando desde los años sesenta, que es, en resumen, la necesidad de un marco referencial para la arquitectura que contemple la experiencia estética, espiritual y social, desde las ciencias de la complejidad, con el propósito de comprender la arquitectura de manera completa, para lo cual suelen emplearse conceptos clave como lenguaje, estructura y sistema.

Para Alexander (2003), el propósito de escribir sus cuatro libros de La naturaleza del orden, es que no se puede tener un punto de vista adecuado 


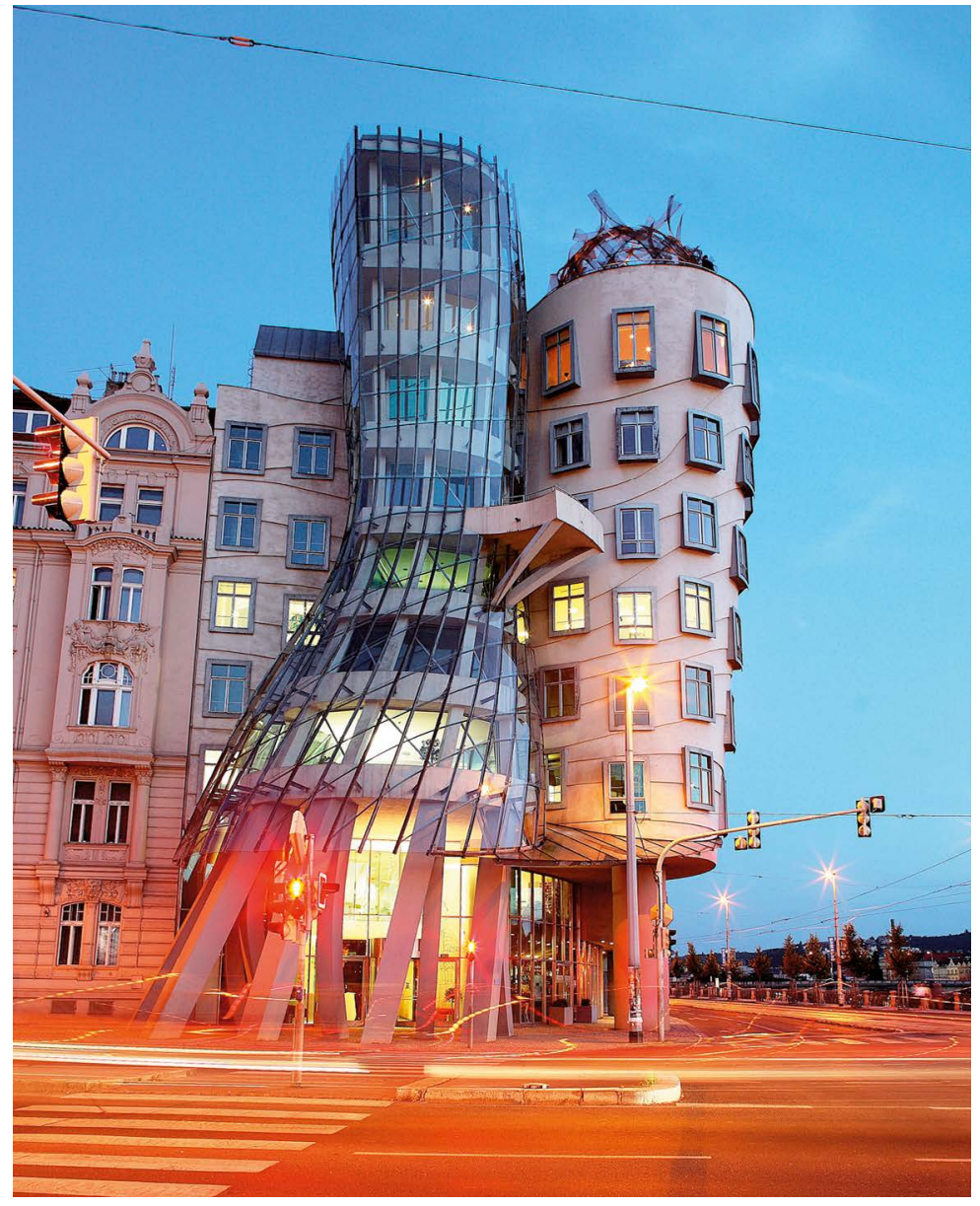

(1) Figura 4. Dancing

House, Praga, 1996. Brado

Milunic y Frank Gehry.

Forma y significado: afán

posmodernista

Fuente: Quinzani (2008).

CC BY-SA 2.0.

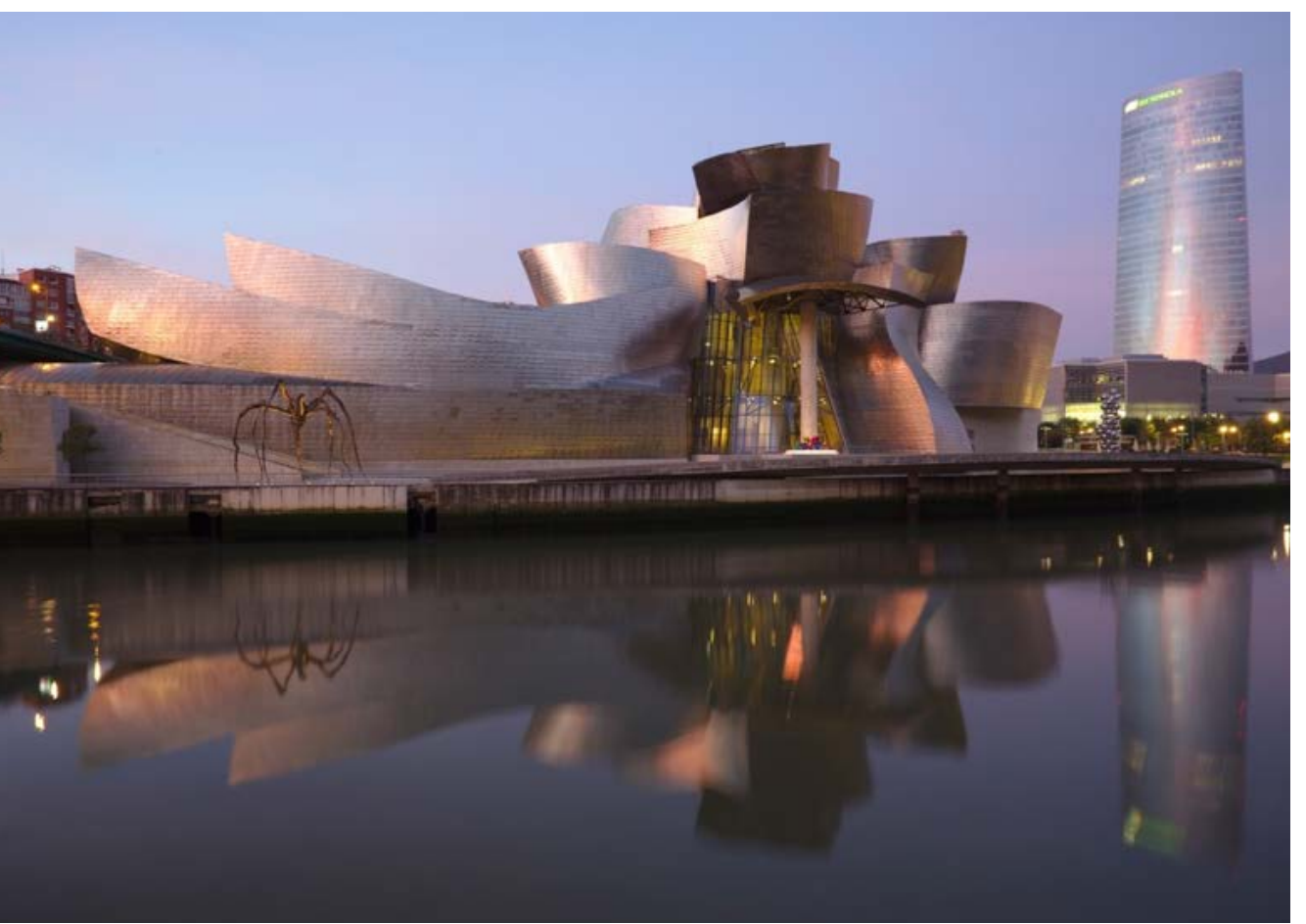

(A) Figura 5. Museo Guggenheim, Bilbao. F. Gehry, 1997. Entre humanismo, tecnología,

significado y experiencia del contexto paisajístico

Fuente: PA, 2015. CC BY-SA 4.0 de la totalidad del espacio edificado si se separan los hechos estéticos o subjetivos, por un lado, y científicos, por otro. Así, para referirse a una totalidad construida se usan conceptos formales para hablar de tectónica y estructura, y conceptos cualitativos para hablar de cómo se experimenta la obra de arquitectura, qué se siente ante sus formas, ante la relación entre las partes y el todo construido, y ante la relación con otras obras construidas, como en el espacio urbano (Figura 4).

Como se argumenta aquí, los conceptos cualitativos empleados en arquitectura en relación con las formas arquitectónicas pueden examinarse mediante su comparación con las Ilamadas metáforas cognitivas, sobre todo cuando se menciona una "antropomorfización" de las formas arquitectónicas al "caracterizarlas mediante términos empleados para designar estados del cuerpo humano", tales como formas pesadas y ligeras, espacios estrechos y anchos, etc. (Norberg-Schulz, 1998, p. 59). De este modo, se tiene la importancia de un modelo fenomenológico y hermenéutico en la medida que la única manera de aproximarse al plano existencial de las emociones y percepciones, y de cómo son entendidas, es mediante metáforas. Citando a Maurice Merleau Ponty, Mallgrave (2013, p. 9) señala la condición corporizada, y las metáforas del cuerpo al estar inmerso en su entorno.

Como ejemplo se tiene que, hablando de la belleza, la función y la forma del espacio arquitectónico, estas categorías entraron en una crisis que para Montaner (2013, pp. 16, 215) hay que referirla como la crisis del objeto autónomo, esto es, "del objeto clásico simétrico y del objeto aislado". Como respuesta a ello surge el objeto moderno como tal, al mismo tiempo que dicha doble y consecutiva crisis del objeto arquitectónico clásico tiene que ver con la creciente importancia del contexto, tanto en lo social, lo urbano, o lo meramente topográfico y paisajístico (p. 18) (Figura 5).

Según lo dicho acerca de los alcances de la nueva tradición, se tiene un cambio de teorías y conceptos ocurrido a partir del Modernismo, donde hay una creciente integración entre ciencias, filosofía y humanidades como recurso para determinar un estatuto epistémico para las emociones y otras experiencias mentales o subjetivas. Además, se tiene un giro o cambio, desde una epistemología cartesiana hacia una constructivista, como se confirma en los resultados de este trabajo.

Si se piensa en el espacio arquitectónico "de un modo fenomenológico" (Davies, 2011), las mismas puertas y ventanas son no solo una cuestión funcional, sino que "se convierten en símbolos de la experiencia humana, de nuestro confinamiento en el cuerpo y de nuestra libertad para explorar el mundo" (p. 67). En otras referencias se ha mencionado también la idea de la casa como una metáfora o imagen arquetípica 


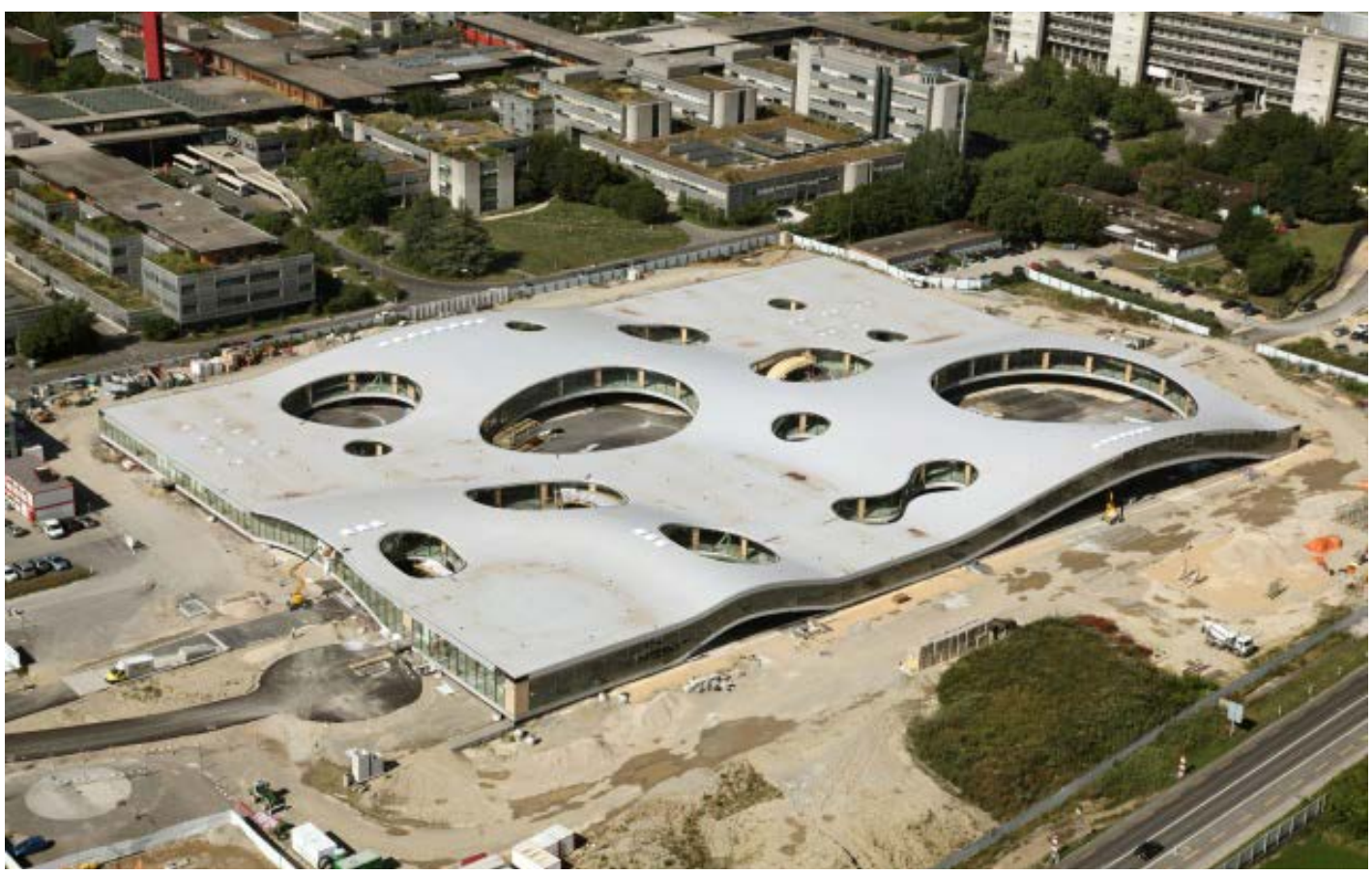

(4) Figura 6. Centro de Entrenamiento Rolex, 2010 Sejima y Nishizawa. Categorías adentro-afuera, y planta libre, en boga

Fuente: Epfll Alain Herzog (2009) Dominio público CO empleada en la fenomenología de Bachelard (Otero-Pailos, 2010, pp. 13,105,106; Pallasmaa, 2011, pp. 10, 97; Pérez-Gómez, 2016, pp. 188189). Según Pérez-Gómez (2016), el proyecto arquitectónico como una propuesta integral puede entenderse como una historia con distintas capas (a multilayered story), con una narrativa poética como parte, que retoma a Paul Ricœur (2003) para abundar en la metáfora como elemento cognitivo distinto a los del pensamiento cartesiano, ya que "la metáfora es el vehículo ideal para hacer presentes los sentimientos".

El cuerpo, la "metáfora corpórea", es fundamental desde un punto de vista cognitivo y experiencial, ya que, en palabras de Tadao Ando (citado por Frampton, 1999, p. 21), "el cuerpo articula al mundo, y al mismo tiempo, el cuerpo es articulado por el mundo". Ando (como Norberg-Schulz, Pallasmaa y Otero-Pailos, entre otros ejemplos), también se acerca a Heidegger y a Merleau-Ponty cuando asevera que "el mundo que aparece a los sentidos humanos y el estado del cuerpo humano son interdependientes" (Frampton, 1999, p. 21), de modo que el mundo circundante es heterogéneo en la medida que el cuerpo humano es asimétrico y, por lo tanto, se organiza a partir de las categorías disyuntivas arriba-abajo, delante-atrás, derecha-izquierda, que al mismo tiempo se constituyen como "imágenes mentales". Siguiendo a Davies, "la arquitectura representa esa corporeidad y ese emplazamiento (ese 'estar ahí') que constituye el fundamento de toda experiencia humana, incluida la experiencia de lo virtual" (2011, p. 152).

El modelo fenomenológico, como se ha dicho, permeó en la geografía constructivista, en la teoría social y en la fenomenología sociológica, como ejemplos en este escrito (Fuentes, 2018), donde la influencia del paradigma de la fenome- nología - por llamarle así- ha venido a más desde mediados del siglo XX.

Además, sería imposible hablar de belleza, o de la estructura perceptual que influye en el estilo arquitectónico o de las funciones del espacio construido, etc., sin tomar en cuenta dicha corporalidad como instrumento de orientación existencial y conceptual (Figura 6).

\section{Discusión}

Se mencionó que la reflexión conceptual y el cambio de teorías se manifiestan como herramientas apropiadas para comprender y explicar las experiencias subjetivas de las personas, esto es, la significación y el sentido del espacio edificado, su dimensión significante y sensorial. Los ejemplos vertidos aquí en cuanto a conceptos como habitar, lugar, espacialidad, vida cotidiana, imagen, metáfora, etc., permiten ampliar un campo de investigación desde distintas propuestas que integran la fenomenología, las humanidades (arte, filosofía) y las neurociencias, buscando respuestas al significado de las emociones.

Así, un primer balance de lo dicho hasta aquí puede resumirse como una nueva comprensión del espacio arquitectónico, y de la complejidad e incertidumbre de nuestro tiempo reflejada en dicho espacio. Vemos que la investigación y crítica de la arquitectura es coetánea de un proceso generalizado de cambio en la historia de la cultura, la ciencia y tecnología, las idea y los conceptos, y el conocimiento mismo. Dicho cambio está ligado a un punto de vista constructivista al cual, si bien se pueden asignársele distintos sentidos, estos pueden distinguirse entre la manera en que se concibe la realidad y la manera en que esta opera, además, cómo se pretende conocerla y qué tipo de conocimiento se espera obtener. 
Entonces, parece más clara la afirmación de que con la Nueva Tradición se está asistiendo al allanamiento de la brecha entre pensamiento y sentimiento, entre razón y emoción, por medio de la puesta en juego de nuevas concepciones y categorías conceptuales respecto de las nociones fundamentales de la arquitectura, aquellas que al mismo tiempo son consustanciales a las categorías lingüísticas y cognitivas, sociales y estructurales, perceptuales y simbólicas, y que se expresan a través de las formas, las estructuras y los estilos arquitectónicos. Y también parece más claro que los principales aportes de la Modernidad para la arquitectura no se enfocaron "en crear objetos abstractos y autónomos sino en pensar en sistemas de relaciones entre los objetos" (Montaner, 2013, p. 215), pero también con la sociedad.

Se advirtió también que esta es, al mismo tiempo, una concepción del mundo y del tiempo, del sujeto y del objeto, y en ese sentido es que se entienden los alcances de la arquitectura con el instrumental de navegación de la complejidad y las humanidades, y con herramientas cognitivas a través de la crítica de conceptos y el cambio de teorías sobre las nociones fundamentales de la arquitectura. Puede verse que dichos conceptos tienen que ver con las categorías fundamentales de la arquitectura -ya señaladas-, entre ellas, las que se refieren a la relación entre las partes y el todo, al espacio-tiempo, sujeto-objeto, así como a otros aspectos de la arquitectura que atañen a sus usos o funciones sociales y a la cuestión formal.

Así se puede entender la afirmación de Frampton de que lo construido es, además de una reflexión conceptual o del proyecto del cual parte su diseño, una representación compleja donde "la inevitable naturaleza terrestre de un edificio posee un carácter tan tectónico y táctil como escenográfico y visual" (1999, p. 13). Aquí la palabra tectónica tiene el sentido de la conjunción de distintas "actividades mixtas, y su culmen es la arquitectura, que surge prácticamente por necesidad y puede ser una representación intensa de los sentimientos más profundos" (p. 15).

Se mencionaron ciertas líneas o áreas de investigación para ampliar nuestra comprensión y conocimiento de las emociones y otras experiencias simbólicas, significantes y cognitivas, subrayando la diferencia entre el modelo cartesiano del conocimiento, por un lado, y la epistemología constructivista y el modelo de la complejidad, por el otro. En tal sentido, desde una óptica cartesiana se pensaría que las emociones y los sentimientos se pueden reducir a procesos cerebrales, que el cerebro es como un procesador o hardware, y que el conocimiento se puede procesar en términos de inteligencia artificial. Por otro parte, se tiene un punto de vista constructivista, que es mostrado aquí en distintas propuestas de integración disciplinar tales como la psicolingüística, la sociología fenomenológica, las neurociencias y los estudios de la cognición (Pérez-Gómez, 2016, pp. 145, 146, 228, 230; Mallgrave, 2013, pp. 34-38, 98, 99; Mallgrave y Goodman, 2011, pp. 229-230).

\section{Conclusiones}

Como puede verse, la nueva tradición en arquitectura, a partir de mediados del siglo XX, representa una fusión o síntesis entre razón y emoción, entre pensamiento y sentimiento, así como un rebasamiento o cambio conceptual que permite entender la compleja interacción entre el espacio edificado o urbano-arquitectónico, y las personas que lo habitan.

Aún quedan pendientes por resolver ciertas cuestiones sobre el movimiento moderno, pues, como menciona Davies (2011, p. 132), debe cuestionarse la idea de los cánones como algo inmutable en la medida que tienen un sesgo histórico-ideológico. En lugar de ello, parece prudente distinguir niveles de análisis y de realidad, según el constructivismo, además de una metodología interdisciplinar, la cual obedece a problemáticas concretas con perspectivas diversas, de acuerdo con las disciplinas participantes. Por ejemplo, respecto de los procesos de diseño urbano y arquitectónico es recomendable considerar cuatro etapas relacionadas entre sí de manera dialógica, según López (2014, p. 30): 1) prefiguración conceptual, 2) procesos materiales, 3) impacto ambiental, y 4) mantenimiento y procesos culturales implicados.

Considerando lo anterior, se concluye que entre la primera y la segunda mitad del siglo XX surgieron nuevas concepciones del espacio influidas por la fenomenología de Heidegger, Gaston Bachelard y Merleau-Ponty, principalmente, que abrieron rutas hacia un cambio de teorías y conceptos en distintas disciplinas interesadas en las relaciones entre la arquitectura y la subjetividad humana. Ello tiene que ver también con la manera en que se entiende el conocimiento, donde se produce un cambio, al asumir un conocimiento experiencial a la hora de emprender cualquier proyecto de diseño urbano-arquitectónico, abriendo rutas hacia una integración disciplinar como en el caso de la geografía humana y el construccionismo social, también influidas por las ciencias de la complejidad y la teoría de sistemas. Como se afirmó, el Modernismo, al proponer un cambio en las concepciones fundamentales de la arquitectura, se acerca a otras disciplinas que, como en geografía, urbanismo, teoría social y humanidades, se interesan por el punto de vista de quienes habitan el espacio edificado; dichas concepciones son un elemento indispensable del diseño urbano y arquitectónico, ya que se relacionan con la vida simbólica o subjetiva de las personas. 
Se recuerda que la inquietud de considerar al espacio construido como una totalidad, o un sistema complejo, según lo señalado por Alexander o Jenks, llevó al primero a implementar un sinnúmero de procesos constructivos que llevasen a crear un ambiente vivo y humano (Alexander, 2012, p. 16). Ello resulta muy actual, por ejemplo, en el caso de Pallasmaa y otros mencionados aquí, para quienes las categorías espaciales son, al mismo tiempo, categorías ontológicas reflejadas en cómo la construcción se levanta entre la tierra y el cielo, según lo señalado a partir de la obra de Norberg-Schulz.
No parece haber duda de que el modelo del constructivismo permitirá seguir indagando y ofreciendo respuestas a la problemática en torno al diseño arquitectónico, mediante la reflexión conceptual y el cambio de teorías, como herramienta para entender nuestro tiempo, y con los principios metodológicos de la complejidad (principios dialógico, de recursividad y hologramático) (López, 2014, pp. 21-22; 2015, pp. 22-24) como instrumentos de orientación en una realidad cambiante y aparentemente caótica.

\section{Referencias}

Alexander, C. (1981). El modo intemporal de construir. Barcelona: Gustavo Gili.

Alexander, C. (2003). New concepts in complexity theory. Arising from studies in the field of architecture. An overview of the four books of The Nature of Order. Katarxis, 3: New Science, New Urbanism, New Architecture. Recuperado de www.natureoforder.com/library/scientific-introduction.pdf

Alexander, C. (2012). The battle for the life and beauty of the earth. A struggle between two world-systems. New York: Oxford University Press.

Davies, C. (2011). Reflexiones sobra la arquitectura. Introducción a la teoría arquitectónica. Barcelona: Reverté.

Quinzani, D. (2008). Le case danzanti di Praga, altrimenti note come "Ginger e Fred" oppure come Tančící dům. [Fotografía] CC BY-SA 2.0. Recuperado de https://www.flickr.com/ photos/37978960@N00/2784812940

Eisenmann, P. (2011). Diez edificios canónicos 1950-2000. Barcelona: Gustavo Gili.

Epfll Alain Herzog (2009). Rolex Learning Center. [Fotografía]. Dominio público. Recuperado de https://es.m.wikipedia.org/wiki/ Archivo:Rolex_Learning_Center_07-2009. jpg

Frampton, K. (1999). Estudios sobre tectónica. Poéticas de la construcción en la arquitectura de los siglos XIX y XX. Madrid: Akal Arquitectura.

Fuentes Farías, F. (2008). Paisajes e itinerarios culturales en Michoacán. Conservación y desarrollo. México: UNAM.

Fuentes Farías, F. (2011). La experiencia cualitativa en el paisaje y el patrimonio construido. Apuntes. Revista de estudios sobre patrimonio cultural, 24(2), 166-177. Recuperado de http://revistas.javeriana.edu.co/index. php/revApuntesArq/article/view/8850

Fuentes Farías, F. (2017). Constructos y paisajes de una ciudad histórica. Contexto, 9(10). Recuperado de http://contexto.uanl.mx/ index.php/contexto/article/view/45

Fuentes Farías, F. (2018). Corporalidad y experiencia como factores de cambio en Arquitectura. De los años 60 a 80 siglo XX. Estoa, 7(12), 113-120. https://doi.org/10.18537/ est.v007.n012.a10

García, R. (2013). Sistemas complejos. Conceptos, método y fundamentación epistemológica de la investigación interdisciplinaria. Barcelona: Gedisa.

Giedion, S. (2009). Espacio, tiempo y arquitectura. Origen y desarrollo de una nueva tradición. Barcelona: Reverté.
Heiddegger, M. (1997). Building, dwelling, thinking. En N. Leach (ed.), Rethinking Architecture (pp. 100-124). London-New York: Routledge.

Highsmith, C. M. Archive (1989). Library of Congress Prints and Photographs Division Washington, D.C. 20540 USA. Vanna Venturi House in Chestnut Hill, Philadelphia. [Fotografía] Co. Recuperado de https:// www.loc.gov/pictures/collection/highsm/ item/2011631329/

Jencks, Ch. (1977). El lenguaje de la arquitectura posmoderna. Barcelona: Gustavo Gili.

Jencks, Ch. (2003a). The Volcano and the Tablet. En CH. Jencks y K. Kropf (eds.), Theories and manifestoes of Contemporary Architecture (pp. 6-13). West Sussex: Wiley-Academy.

Jencks, Ch. (2003b). Semiology and Architecture. En CH. Jencks y K. Kropf (eds.), Theories and manifestoes of Contemporary Architecture (pp. 43-46). Chichester: Academy Editions.

Jencks, Ch. (2011). The Story of Post-Modernism. West Sussex: Wiley.

Lindón, A. (2012). La concurrencia de lo especial y lo social. En E. de la Garza Toledo y G. Leyva (coords.). Tratado de metodología de las ciencias sociales: perspectivas actuales (pp. 585-622). México: Fondo de Cultura Económica-UAM.

Lindón, A. (2014). El habitar la ciudad, las redes topológicas del urbanista y la figura del transeúnte. En D. Sánchez y L. A. Domínguez (coords.). Identidad y espacio público. Ampliando ámbitos y prácticas (pp. 55-76). Barcelona: Gedisa. Recuperado de https:// dialnet.unirioja.es/servlet/libro?codigo $=562576$

López, R. (2014). Hacia una conceptualización del diseño basada en el pensamiento complejo. En R. López, F. Platas López, G. Romero Fernández y J. U. Salceda Salinas, La complejidad y la participación en la producción de arquitectura y ciudad. (pp. 15-59). México: UNAM.

López, R. (2015). Una visión compleja de los procesos de urbanización de la capital de la República. En R. López Rangel y R. A. Tena Núñez (coord.), Los nuevos paradigmas en los análisis urbanos. Complejidad y urbanización sociocultural en la Ciudad de México (pp. 15-51). México: UAM-IPN.

Mallgrave, F. H. (2013). Architecture and Embodiment. The implications of the New Sciences and Humanities for Design. London-New York: Routledge.
Mallgrave, H. F. y Goodman, D. (2011). An Introduction to Architectural Theory. 1968 to the present. Oxford: Wiley-Blackwell.

Montaner, J. M. (2010). Arquitectura y crítica (2 ed.). Barcelona: Gustavo Gili.

Montaner, J. M. (2013). Sistemas arquitectónicos contemporáneos (2 ed.) Barcelona: Gustavo Gili.

Montaner, J. M. (2014). Del diagrama a las experiencias, hacia una arquitectura de la acción. Barcelona: Gustavo Gili.

Montaner, J. M. (2015). La condición contemporánea de la arquitectura. Barcelona: Gustavo Gili.

Norberg-Schulz, C. (1998). Intenciones en arquitectura (2 ed.). Barcelona: Gustavo Gilli.

Norberg-Schulz, C. (2005). Los principios de la arquitectura moderna. Barcelona: Reverté.

Otero-Pailos, J. (2010). Architecture's Historical Turn. Fenomenology and the rise of Postmodern. Minneapolis: University of Minnesota Press.

Pallasmaa, J. (2011). The Embodied Image. Imagination and Imagery in Architecture. West Sussex: John Wiley \& Sons.

Pallasmaa, J. (2016). Habitar. Barcelona: Gustavo Gili.

Pauortizsat (2013). Planta baja Casa Vanna Venturi. [Plano]. CC BY-SA 3.0. Recuperado de https://es.wikipedia.org/wiki/Archivo:Casa_Vanna_Venturi_Planos_2.jpg

Pérez-Gómez, A. (2016). Attunement. Architectural Meaning after the crisis of Modern Science. Cambridge: The MIT Press.

Ricœur, P. (2003). Teoría de la interpretación. Discurso y excedente de sentido. México: Siglo XXI.

Schaefer, H. P. (1999). Barcelona, Deutscher Weltausstellungspavillon 1929 (Rekonstruktion), Detail 2, Architekt: Mies van der Rohe. [Fotografía]. CC BY-SA 3.0. Recuperado de https://es.wikipedia.org/wiki/ Ludwig Mies van der Rohe\#/media/File:Barcelona_mies_v_d_rohe_pavillon_weltausstellung-1999_03.jpg

Summerson, J. (1963). El lenguaje clásico de la arquitectura: de L. B. Alberti a Le Corbusier. Barcelona: Gustavo Gili.

Venturi, R. (1995 [1966]). Complejidad y contradicción en la arquitectura ( $\left.2^{\mathrm{a}} \mathrm{ed}\right)$. Barcelona: Gustavo Gili.

Zevi, B. (2010 [1973]). El lenguaje moderno de la arquitectura. Barcelona: Apóstrofe. 


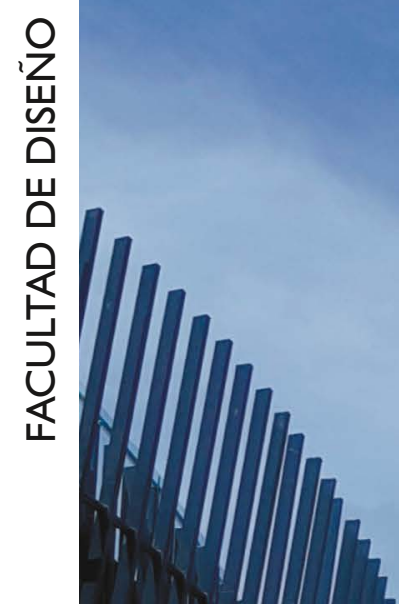

Vol.

\section{Nro. 1REVISTA DE ARQUITECTURA}
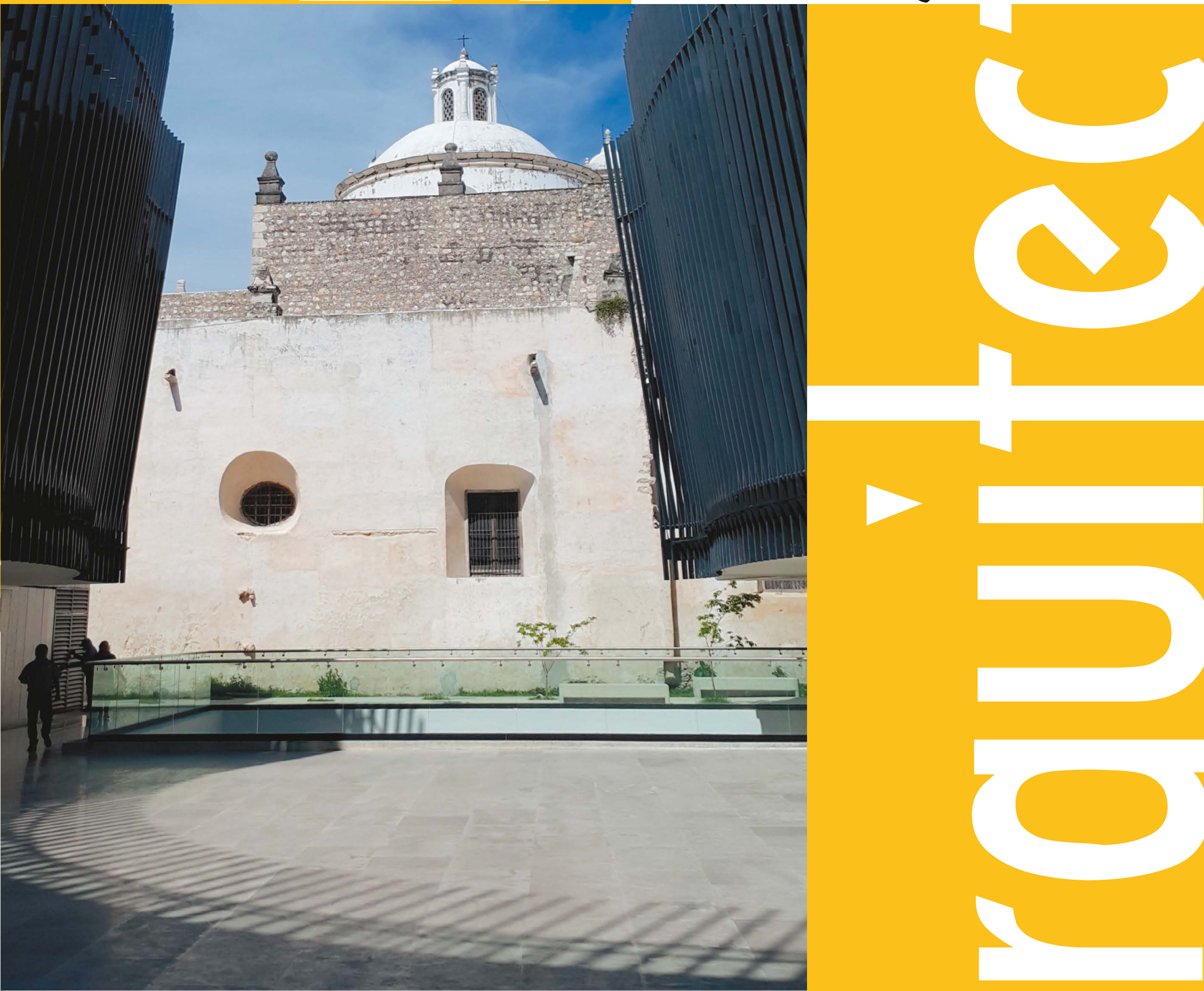
A) Portada: Palacio de la Música y Rectoria El J Júśs Tercera Orden. Mérida, Yucatán (México).

Fotografía: César Eligio-Triana (2018, septiembre) CC BY-NC

\section{(c) (1) ( $)$}

A Orientación editorial

\section{Enfoque y alcance}

La Revista de Arquitectura (Bogotá) ( (ISSN 1657-0308 Impresa y E-ISSN 2357-626X en línea) es una publicación seriada de acceso abierto, arbitrada mediante revisión por pares (doble ciego) e indexada, en donde se publican resultados de investigación originales e inéditos.

Está dirigida a la comunidad académica y profesional de las áreas afines a la disciplina. Es editada por la Facultad de Diseño y el Centro de Investigaciones (CIFAR) de la Universidad Católica de Colombia en Bogotá (Colombia).

La principal área científica a la que se adscribe la Revista de Arquitectura (Bogotá) según la OCDE es:

Gran área: 6. Humanidades

Área: 6.D. Arte

\section{Disciplina: 6D07. Arquitectura y Urbanismo}

También se publican artículos de las disciplinas como 2A02, Ingeniería arquitectónica; 5G03, Estudios urbanos (planificación y desarrollo); 6D07, Diseño.

Los objetivos de la Revista de Arquitectura (Bogotá) son:

- Promover la divulgación y difusión del conocimiento generado a nivel local, nacional e internacional

- Conformar un espacio para la construcción de comunidades académicas y la discusión en torno a las secciones definidas.

- Fomentar la diversidad institucional y geográfica de los autores que participan en la publicación.

- Potenciar la discusión de experiencias e intercambios científicos entre investigadores y profesionales.

- Contribuir a la visión integral de la arquitectura, por medio de la concurrencia y articulación de las secciones mediante la publicación de artículos de calidad.

- Publicar artículos originales e inéditos que han pasado por revisión de pares, para asegurar que se cumplen las normas éticas, de calidad, validez científica, editorial e investigativa.

- Fomentar la divulgación de las investigaciones y actividades desarrolladas en la Universidad Católica de Colombia.
Palabras clave de la Revista de Arquitectura (Bogotá): arquitectura, diseño, educación arquitectónica, proyecto y construcción, urbanismo.

Idiomas de publicación: español, inglés, portugués y francés. Título abreviado: Rev. Arquit.

\section{Titulo corto: RevArq}

\section{Políticas de sección}

La revista se estructura en tres secciones correspondientes a las líneas de investigación activas y aprobadas por la institución, y dos complementarias, que presentan dinámicas propias de la Facultad de Diseño y las publicaciones relacionadas con la disciplina.

Cultura y espacio urbano. En esta sección se publican los artículos que se refieren a fenómenos sociales en relación con el espacio urbano, atendiendo aspectos de la historia, el patrimonio cultural y físico, y la estructura formal de las ciudades y el territorio.

Proyecto arquitectónico y urbano. En esta sección se presentan artículos sobre el concepto de proyecto, entendido como elemento que define y orienta las condiciones proyectuales que devienen en los hechos arquitectónicos o urbanos, y la forma como estos se convierten en un proceso de investigación y nuevo de conocimiento. También se presentan proyectos que sean resultados de investigación, los cuales se validan por medio de la ejecución y transformación en obra construida del proceso investigativo. También se contempla la publicación de investigaciones relacionadas con la pedagogía y didáctica de la arquitectura, el urbanismo y el diseño.

Tecnología, medioambiente y sostenibilidad. En esta sección se presentan artículos acerca de sistemas estructurales, materiales y procesos constructivos, medioambiente y gestión, relacionados con los entornos social-cultural, ecológico y económico.

Desde la Facultad. En esta sección se publican artículos generados en la Facultad de Diseño, relacionados con las actividades de docencia, extensión, formación en investigación o internacionalización, las cuales son reflejo de la dinámica y de las actividades realizadas por docentes, estudiantes y egresados; esta sección no puede superar el $20 \%$ del contenido.

Textos. En esta sección se publican reseñas, traducciones y memorias de eventos relacionados con las publicaciones en Arquitectura y Urbanismo.

\section{A Frecuencia de publicación}

Desde 1999 y hasta el 2015, la Revista de Arquitectura (Bogotá) publicó un volumen al año, a partir del 2016 se publicarán dos números por año en periodo anticipado, enero-junio y julio-diciembre, pero también maneja la publicación anticipada en línea de los artículos aceptados (versión Post-print del autor).

La Revista de Arquitectura (Bogotá) se divulga mediante versiones digitales (PDF, HTML, EPUB, XML) e impresascon un tiraje de 700 ejemplares, los tiempos de producción de estas versiones dependerán de los cronogramas establecidos por la editorial.

Los tiempos de recepción-revisión-aceptación pueden tardar entre seis y doce meses dependiendo del flujo editorial de cada sección y del proceso de revisión y edición adelantado.

Con el usuario y contraseña asignados, los autores pueden ingresar a la plataforma de gestión editorial y verificar el estado de revisión, edición o publicación del artículo.
A Canje

La Revista de Arquitectura (Bogotá) está interesada en establecer canje con publicaciones académicas, profesionales o científicas del área de Arquitectura y Urbanismo, como medio de reconocimiento y discusión de la producción científica en el campo de acción de la publicación.

\section{Mecanismo}

Para establecer canje por favor descargar, diligenciar y enviar el formato: RevArq FP20 Canjes

\section{Universidad Católica de Colombia (2019, enero-junio). Revista de Arquitectura (Bogotá), $2 I(\mathrm{I})$ I-120. Doi: 10.14718 \\ ISSN: 1657-0308 E-ISSN: 2357-626X \\ Especificaciones: Formato: $34 \times 24 \mathrm{~cm}$ Papel: Mate $115 \mathrm{~g}$ Tintas: Negro y policromía}

A Contacto

Dirección postal:

Avenida Caracas No. 46-72.

Universidad Católica de Colombia

Bogotá D.C.(Colombia)

Código postal: 111311

Facultad de Diseño

Centro de Investigaciones (CIFAR).

Sede El Claustro. Bloque "L", 4 piso

Diag. 46a No. $15 b-10$

Editor, Arq. César Eligio-Triana

Teléfonos:

+57 (1) $3277300-3277333$

Ext. $3109 ; 3112$ o 5146

Fax: +57 (1) 2858895
Correo electrónico:

revistadearquitectura@ucatolica.edu.co

cifar@ucatolica.edu.co

Página WEB:

www.ucatolica edu.co

vínculo Revistas científicas

http://publicaciones.ucatolica.edu.co revistas-cientificas

http://editorial.ucatolica.edu.co/ojsucatolica/revistas_ucatolica/index.php/RevArq 
Universidad Católica de Colombia

Presidente

Édgar Gómez Betancourt

Vicepresidente - Rector

Francisco José Gómez Ortiz

Vicerrector Jurídico

Edwin de Jesús Horta Vásquez

Vicerrector Administrativo

Édgar Gómez Ortiz

Vicerrector Académico

Elvers Medellín Lozano

Vicerrector de Talento Humano

Ricardo López Blum

Director de Investigaciones

Edwin Daniel Durán Gaviria

Directora Editorial

Stella Valbuena García

\section{Facultad de Diseño}

Decano

Werner Gómez Benítez

Director de docencia

Jorge Gutiérrez Martínez

Directora de extensión

Mayerly Rosa Villar Lozano

Director de investigación

Hernando Verdugo Reyes

Director de gestión de calidad

Augusto Forero La Rotta

Comité asesor externo

Facultad de Diseño

Édgar Camacho Camacho

Martha Luz Salcedo Barrera

Samuel Ricardo Vélez
Facultad de Diseño

Centro de Investigaciones - CIFAR

\section{REVISTA DE ARQUITECTURA \\ Revista de Arquitectura \\ (Bogotá)}

Revista de acceso abierto,

arbitrada e indexada

Publindex: Categoría B. Índice Bibliográfico Nacional IBN.

Esci: Emerging Source Citation Index.

Doaj: Directory of Open Access Journals.

Redalyc: Red de Revistas Cientificas de América Latina y el Caribe,

España y Portugal.

SciELO: Scientific Electronic Library Online - Colombia

Redib: Red Iberoamericana de Innovación y Conocimiento Cientifico.

Ebsco: EBSCOhost Research Databases.

Clase: Base de datos bibliográfica de revistas de ciencias sociales y

humanidades.

Latindex: Sistema Regional de Información en Línea para Revistas

Científicas de América Latina, el Caribe, España y Portugal (Directorio

y catálogo).

Dialnet: Fundación Dialnet - Biblioteca de la Universidad de La Rioja.

LatinRev: Red Latinoamericana de Revistas Académicas en Ciencias

Sociales $y$ Humanidades.

Proquest: ProQuest Research Library.

Miar: Matrix for the Analysis of Journals.

Sapiens Research: Ranking de las mejores revistas colombianas según

visibilidad internacional.

Actualidad Iberoamericana: (Índice de Revistas) Centro de Información

Tecnológica (CIT).

Google Scholar

Arla: Asociación de Revistas latinoamericanas de Arquitectura.

\section{Editorial}

Av. Caracas № 46-72, piso 5

Teléfono: 3277300 Ext. 5145

editorial@ucatolica.edu.co

www.ucatolica.edu.co

http://publicaciones.ucatolica.edu.co)

Impresión:

JaVEGRAF

Calle 46A No82-54 Int. 2

Bogotá, D. C., Colombia

http://www.javegraf.com.co/index.php

Enero de 2019
Director

Werner Gómez Benítez

Editor

César Eligio-Triana

Editores de sección

(1) Myriam Stella Díaz-Osorio

(1) Carolina Rodríguez-Ahumada

(4) Anna Maria Cereghino-Fedrigo

\section{Equipo editorial}

Coordinadora editorial

María Paula Godoy Casasbuenas

mpgodoy@ucatolica.edu.co

Diseño y montaje

Juanita Isaza

juanaisaza@gmail.com

Traductoras

Inglés

Erika Tanacs

etanacs25@gmail.com

Portugués

Roanita Dalpiaz

roanitad@gmail.com

Correctora de estilo

María José Díaz Granados M.

mariajose_dgm@yahoo.com.co

Página Web

Centro de investigaciones (CIFAR)

Distribución y canjes

Claudia Álvarez Duquino

calvarez@ucatolica.edu.co
Comité editorial y científico

Cultura y espacio urbano

Carlos Mario Yory, PhD

Universidad Católica de Colombia. Bogotá, Colombia

Sonia Berjman, $\mathrm{PhD}$

ICOMOS-IFLA, Buenos Aires, Argentina

Juan Carlos Pérgolis, MSc Universidad Piloto de Colombia. Bogotá, Colombia

Beatriz García Moreno, PhD

Universidad Nacional de Colombia. Bogotá, Colombia

Proyecto arquitectónico y urbano

Jean-Philippe Garric, PhD, HDR

Université Paris I Panthéon-Sorbonne. Paris, Francia

Debora Domingo Calabuig, PhD

Universidad Politécnica de Valencia, España

Dania González Couret, PhD

Universidad Tecnológica de La Habana, Cuba

Hugo Mondragón López, PhD Pontificia Universidad Católica de Chile. Santiago, Chile

Juan Pablo Duque Cañas, PhD

Universidad Nacional de Colombia. Bogotá, Colombia

Tecnología, medioambiente y sostenibilidad

Mariano Vázquez Espí, PhD

Universidad Politécnica de Madrid, España

Denise Helena Silva Duarte, PhD Universidade de São Paulo (USP), Brasil

Luis Carlos Herrera Sosa, PhD Universidad Autónoma de Ciudad Juárez, México

Claudio Varini, PhD

Universidad Católica de Colombia. Bogotá, Colombia

Luis Gabriel Gómez Azpeitia, PhD Universidad de Colima. Colima, México 


\section{CONTENIDO}
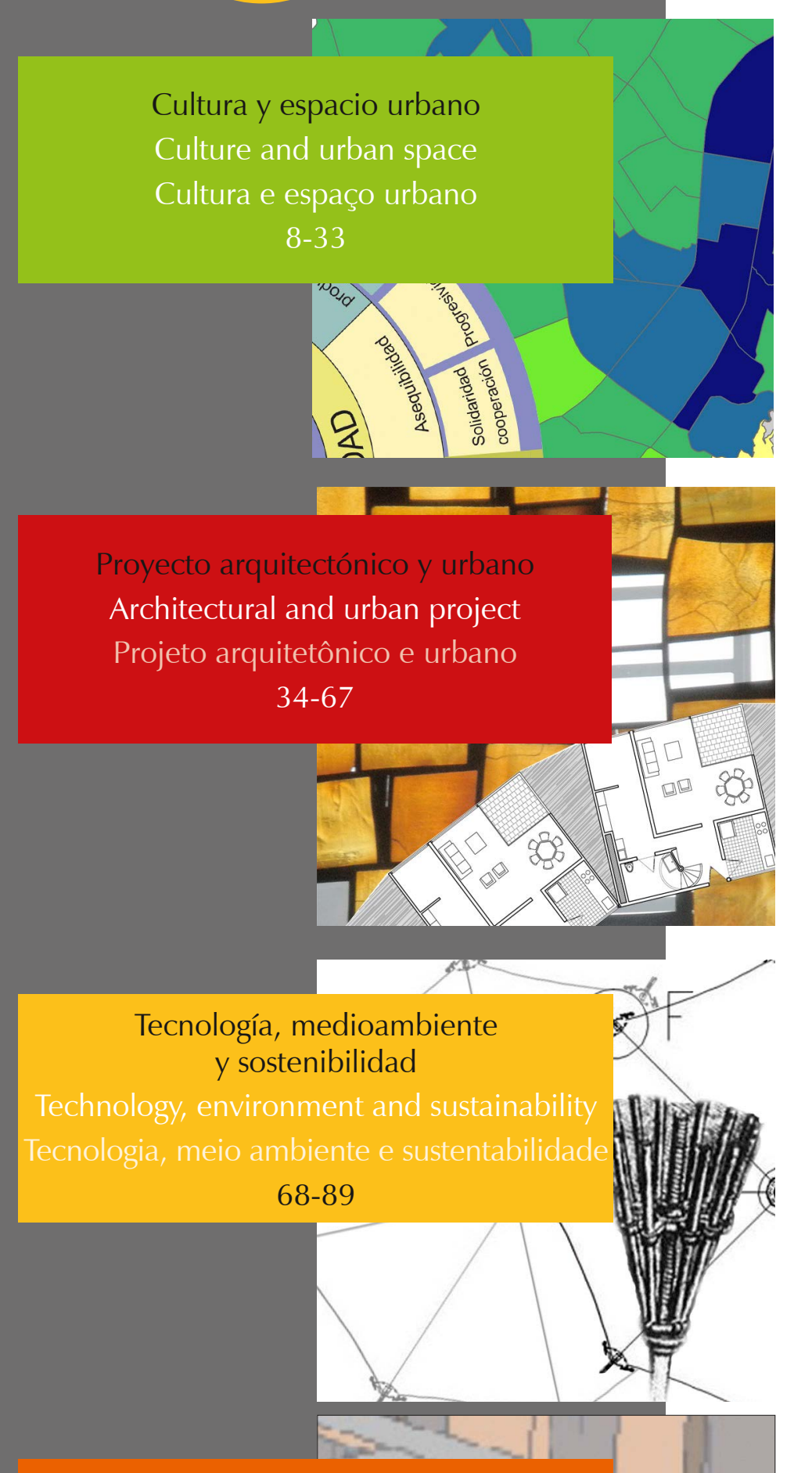

Desde la Facultad

From the Faculty

Da faculdade

90-109

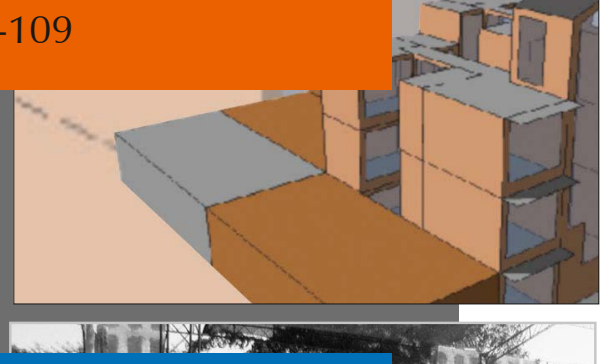

Textos

Texts

Textos

110-118
Revistas en tiempos tecno-humanos

Julio Arroyo

Pág. 3

ES

Índice de caminabilidad para la ciudad de Bogotá

Julián Alberto Gutiérrez-López
Yolanda Beatriz Caballero-Pérez
Rubén Alejandro Escamilla-Triana

ES

Pág. 8

Principios, criterios y propósitos de desarrollo sustentable para la redensificación en contextos urbanos informales
Juan José Castiblanco-Prieto
Fabián Adolfo Aguilera-Martínez
Fabián Alonso Sarmiento-Valdés

Pág. 21

ES

Complejidad y constructivismo en la nueva tradición de la arquitectura de la posguerra

Francisco Javier Fuentes-Farías

Pág. 34 ES

Conservación del arte contemporáneo

El caso de Mathias Goeritz en la Catedral

Metropolitana de México

Alberto Cedeño-Valdiviezo

Pablo Torres-Lima

Pág. 44

\section{ES EN}

Operando desde la forma: un procedimiento

para la valoración de la vivienda colectiva

Julián Camilo Valderrama-Vidal

Pág. 54

ES

Disponibilidad de las técnicas constructivas

de habitación en madera, en Brasil

Victor A. De Araujo

Carlos M. Gutiérrez-Aguilar

Juliana Cortez-Barbosa

Maristela Gava

José N. Garcia

Pág. 68

ES

Diseño y construcción de un paraguas plegable para espacios arquitectónicos

Carlos César Morales-Guzmán

Pág. 76

ES EN

Envolventes eficientes

Relación entre condiciones ambientales, espacios confortables

y simulaciones digitales

Natalia Medina-Patrón

Jonathan Escobar-Saiz

Pág. 90

ES

(Re)pensando el enfoque tecnológico:

el caso del Centro Experimental de la Vivienda

Económica (CEVE) en Argentina

Gustavo Pelegrin

Laila Fleker

Aurelio Ferrero

Pág.110 
La postulación de un artículo a la Revista de Arquitectura (Bogotá) indica que- el o los autores certifican que conocen y aceptan la política editorial, para lo cual firmarán en original y remitirán el formato RevArq FP00 Carta de originalidad.

La Revista de Arquitectura (Bogotá) maneja una política de Autoarchivo VERDE, según las directrices de SHERPA/RoMEO, por lo cual el autor puede:

- Pre-print del autor: Archivar la versión pre-print (la versión previa a la revisión por pares

- Post-print del autor: Archivar la versión post-print (la versión final posterior a la revisión por pares

- Versión de editor/PDF: Archivar la versión del editor - PDF/HTML/XLM en la maqueta de la Revista de Arquitectura (Bogotá).

El Autoarchivo se debe hacer respetando la licencia de acceso abierto, la integridad y la imagen de la Revista de Arquitectura (Bogotá), también se recomienda incluir la referencia, el vínculo electrónico y el DOI.

El autor o los autores son los titulares del Copyright (c) del texto publicado y la Editorial de la Revista de Arquitectura (Bogotá) solicita la firma de una autorización de reproducción del artículo (RevArq FP03 Autorización reproducción), la cual se acoge a la licencia CC, donde se expresa el derecho de primera publicación de la obra.

La Revista de Arquitectura (Bogotá) se guía por las normas internacionales sobre propiedad intelectual y derechos de autor, y de manera particular el artículo 58 de la Constitución Política de Colombia, la Ley 23 de 1982 y el Acuerdo 172 del 30 de septiembre de 2010 (Reglamento de propiedad intelectual de la Universidad Católica de Colombia)

Para efectos de autoría y coautoría de artículos se diferencian dos tipos: "obra en colaboración" y "obra colectiva". La primera es aquella cuya autoría corresponde a todos los participantes al ser fruto de su trabajo conjunto. En este caso, quien actúa como responsable y persona de contacto debe asegurar que quienes firman como autores han revisado y aprobado la versión final, y dan consentimiento para su divulgación. La obra colectiva es aquella en la que, aunque participan diversos colaboradores, hay un autor que toma la iniciativa la coordinación y realización de dicha obra. En estos casos, la autoría corresponderá a dicha persona (salvo pacto en contrario) y será suficiente únicamente con su autorización de divulgación.

El número de autores por artículo debe estar justificado por el tema, la complejidad y la extensión, y no deberá ser superior a la media de la disciplina, por lo cual se recomienda que no sea mayor de cinco. El orden en que se enuncien corresponderá a los aportes de cada uno a la construcción del texto, se debe evitar la autoría ficticia o regalada. Si se incluyen más personas que trabajaron en la investigación se sugiere que sea en calidad de colaboradores o como parte de los agradecimientos. La Revista de Arquitectura (Bogotá) respetará el número y el orden en que figuren en el original remitido. Si los autores consideran necesario, al final del artículo pueden incluir una breve descripción de los aportes individuales de cada uno de firmantes.

La comunicación se establece con uno de los autores, quien a su vez será el responsable de informar a los demás autores de las notificaciones emitidas por la Revista de Arquitectura (Bogotá).

En virtud de mantener el equilibro de las secciones y las mismas oportunidades para todos los participantes, un mismo autor puede postular dos o más artículos de manera simultánea; si la decisión editorial es favorable y los artículos son aceptados, su publicación se realizará en números diferentes.

\section{A Acceso abierto}

La Revista de Arquitectura (Bogotá), en su misión de divulgar la investigación y apoyar el conocimiento y la discusión en los campos de interés, proporciona acceso abierto, inmediato e irrestricto a su contenido de manera gratuita mediante la distribución de ejemplares impresos y digitales. Los interesados pueden leer, descargar, guardar, copiar y distribuir, imprimir, usar, buscar o referenciar el texto completo o parcial de los artículos o la totalidad de la Revista de Arquitectura (Bogotá).

\section{(c) (1) (3)}

Esta revista se acoge a la licencia Creative Commons (CC BY NC de Atribución - No comercial 4.0 Internacional): "Esta licencia permite a otros entremezclar, ajustar y construir a partir de su obra con fines no comerciales, y aunque en sus nuevas creaciones deban reconocerle su autoría y no puedan ser utilizadas de manera comercial, no tienen que estar bajo una licencia con los mismos términos".

La Revista de Arquitectura es divulgada en centros y grupos de investigación, en bibliotecas y universidades, y en las principales facultades de Arquitectura mediante acceso abierto a la versión digital y suscripción anual al ejemplar impreso o por medio de canje, este último se formaliza mediante el formato RevArq FP20 Canjes

Para aumentar su visibilidad y el impacto de los artículos, se envían a bases de datos y sistemas de indexación y resumen (SIR) y, asimismo, pueden ser consultados y descargados en la página web de la revista.

La Revista de Arquitectura no maneja cobros, tarifas o tasas de publicación de artículo (Article Processing Charge-APC), o por el sometimiento de textos a la publicación.

\section{(A) Ética y buenas prácticas}

La Revista de Arquitectura se compromete a cumplir y respetar las normas éticas en todas las etapas del proceso de publicación. Los autores de los artículos publicados darán cumplimiento a los principios éticos contenidos en las diferentes declaraciones y legislaciones sobre propiedad intelectual y derechos de autor específicos del país donde se realizó la investigación. En consecuencia, los autores de los artículos postulados y aceptados para publicar, que presentan resultados de investigación, deben firmar la declaración de originalidad (formato RevArq FP00 Carta de originalidad).

La Revista de Arquitectura reconoce y adopta los principios de transparencia y buenas prácticas descritos por COPE, "Principles of Transparency and Best Practice in Scholarly Publishing" (2015).

El equipo editorial tiene la obligación de guardar la confidencialidad acerca de los artículos recibidos, y abstenerse de usar en sus propias investigaciones datos, argumentos o interpretaciones hasta tanto el artículo no sea publicado. También debe ser imparcial y gestionar los artículos de manera adecuada y en los plazos establecidos. La selección de revisores se hará con objetividad y estos deberán responder a la temática del artículo.

El editor, los autores y los revisores deben seguir las normas éticas internacionales definidas por el Committee on Publication Ethics (COPE), con el fin de evitar casos de:

- Fabricación, falsificación u omisión de datos.

- Plagio y autoplagio.

- Publicación redundante, duplicada o fragmentada.

- Omisión de referencias a las fuentes consultadas.

- Utilización de contenidos sin permiso o sin justificación.

- Apropiación individual de autoría colectiva.

- Cambios de autoría.

- Conflicto de interés (CDI) no revelado o declarado.

- Otras que pudieran surgir en el proceso de investigación y publicación. La fabricación de resultados se genera al mostrar datos inventados por los autores; la falsificación resulta cuando los datos son manipulados y cambiados a capricho de los autores; la omisión se origina cuando los autores ocultan deliberadamente un hecho o dato. El plagio se da cuando un autor presenta como ideas propias datos creados por otros. Los casos de plagio son los siguientes: copia directa de un texto sin entrecomillar o citar la fuente, modificación de algunas palabras del texto, paráfrasis y falta de agradecimientos; el autoplagio se da cuando el mismo autor reutiliza material propio que ya fue publicado, pero sin indicar la referencia al trabajo anterior. La revista se apoya en herramientas digitales que detectan cualquiera de estos casos en los artículos postulados, y es labor de los editores y revisores velar por la originalidad y fidelidad en la citación. La publicación redundante o duplicada se refiere a la copia total, parcial o alterada de un trabajo ya publicado por el mismo autor

En caso de sospechar de alguna mala conducta se recomienda seguir los diagramas de flujo elaborados por COPE (2008), con el fin de determinar las acciones correspondientes.

La Revista de Arquitectura se reserva el derecho de retractación de publicación de aquellos artículos que, posterior a su publicación, se demuestre que presentan errores de buena fe, o cometieron fraudes o malas prácticas científicas. Esta decisión se apoyará en "Retraction Guidelines" (COPE, 2009). Si el error es menor, este se podrá rectificar mediante una nota editorial de corrección o una fe de erratas. Los autores también tienen la posibilidad de solicitar la retractación de publicación cuando descubran que su trabajo presenta errores graves. En todos los casos se conservará la versión electrónica y se harán las advertencias de forma clara e inequívoca.

\section{A Privacidad y manejo de la información.} Habeas Data

Para dar cumplimiento a lo previsto en el artículo 10 del Decreto 1377 de 2013, reglamentario de la Ley 1581 de 2012, y según el Acuerdo 002 del 4 de septiembre de 2013 de la Universidad Católica de Colombia, "por el cual se aprueba el manual de políticas de tratamiento de datos personales":

La Universidad Católica de Colombia, considerada como responsable o encargada del tratamiento de datos personales, manifiesta que los datos personales de los autores, integrantes de los comités y pares revisores, se encuentran incluidos en nuestras bases de datos; por lo anterior, y en cumplimiento de las disposiciones legales vigentes, la Universidad solicitará siempre su autorización, para que en desarrollo de sus funciones propias como Institución de Educación Superior, en especial las relacionadas con la docencia, la extensión y la investigación, la Universidad Católica de Colombia pueda recolectar, recaudar, almacenar, usar, circular, suprimir, procesar, intercambiar, compilar, dar tratamiento, actualizar, transmitir o transferir a terceros países y disponer de los datos que le han suministrado y que han sido incorporados en las bases de datos de todo tipo que reposan en la Universidad.

La Universidad Católica de Colombia queda autorizada, de manera expresa e inequívoca, en los términos señalados por el Decreto 1377 de 2013, para mantener y manejar la información de nuestros colaboradores (autores, integrantes de los diferentes comités y pares revisores); así mismo, los colaboradores podrán ejercer sus derechos a conocer, actualizar, rectificar y suprimir sus datos personales, para lo cual se han dispuesto las siguientes cuentas de correo electrónico: 
La Revista de Arquitectura (Bogotá) recibe artículos de manera permanente. Los artículos se procesan a medida que se postulan, dependiendo el flujo editorial de cada sección.

El idioma principal es el español, y como opcionales están definidos el inglés, el portugués y el francés; los textos pueden ser escritos y presentados en cualquiera de estos.

Los artículos postulados deben corresponder a las categorías universalmente aceptadas como producto de investigación, ser originales e inéditos y sus contenidos responder a criterios de precisión, claridad y brevedad.

Como punto de referencia se pueden tomar las tipologías y definiciones del Îndice Bibliográfico Nacional, Publindex (2010) que se describen la continuación:

1. Artículo de revisión: documento resultado de una investigación terminada donde se analizan, sistematizan e integran los resultados de investigaciones publicadas o no publicadas, sobre un campo en ciencia o tecnología, con el fin de dar cuenta de los avances y las tendencias de desarrollo. Se caracteriza por presentar una cuidadosa revisión bibliográfica de por lo menos 50 referencias.
2. Artículo de investigación científica y tecnológica: documento que presenta, de manera detallada, los resultados originales de proyectos terminados de investigación. La estructura generalmente utilizada contiene cuatro apartes importantes: introducción, metodología, resultados y conclusiones.

3. Artículo de reflexión: documento que presenta resultados de investigación terminada desde una perspectiva analítica, interpretativa o crítica del autor, sobre un tema específico, recurriendo a fuentes originales.

Adicional a estas tipologías, se pueden presentar otro tipo de artículos asociados a procesos de investigación-creación y/o investigación proyectual. En todos los casos se debe presentar la información suficiente para que cualquier investigador pueda reproducir la investigación y confirmar o refutar las interpretaciones defendidas y sea evidente el aporte a la disciplina.

En todos los casos se debe presentar la información suficiente para que cualquier investigador pueda reproducir la investigación y confirmar o refutar las interpretaciones defendidas.

\section{(A) Instrucciones para postular artículos}

Postular el artículo en la página web de la Revista de Arquitectura (Bogotá) y adjuntar comunicación escrita dirigida al editor RevArq_FP00 Carta de originalidad (debidamente firmada por todos los autores en original); de igual manera, se debe diligenciar el formato de hoja de vida RevArq FP01 Hoja de Vida (una por cada autor).

En la comunicación escrita el autor expresa que conoce y acepta la política editorial de la Revista de Arquitectura (Bogotá), que el artículo no está postulado para publicación simultáneamente en otras revistas u órganos editoriales y que no existe conflicto de intereses (ver modelo RevArq FP06 CDI) y que, de ser aceptado, concederá permiso de primera publicación, no exclusiva a nombre de la Universidad Católica de Colombia como editora de la revista.

Los artículos deben tener en cuenta las siguientes recomendaciones:

- En la primera página del documento se debe incluir:

Tírulo: no exceder 15 palabras

Subtítulo: opcional, complementa el título o indica las principales subdivisiones del texto.

Nombre del autor o autores: nombres y apellidos completos o según modelo de citación adoptado por el autor para la normalización de los nombres del investigador. Como nota al pie (máximo 100 palabras) formación académica, experiencia profesional e investigativa, código ORCID https://orcid.org/, e información de contacto, correo electrónico.

Filiación institucional: debajo del nombre se debe declarar la ins-titución en la cual se desarrolló el producto, de la cual recibió apoyo o aquella que respalda el trabajo investigativo.

Resumen: debe ser analítico, se redacta en un solo párrafo, da cuenta del tema, el objetivo, la metodología, los resultados y las conclusiones; no debe exceder las 150 palabras.

Palabras clave: cinco palabras o grupo de palabras, ordenadas alfabéticamente y que no se encuentren en el título o subtítulo; estas sirven para clasificar temáticamente al artículo. Se recomienda emplear principalmente palabras definidas en el tesauro de la Unesco (http://databases. unesco.org/thessp/), en el tesauro de Arte \& Arquitectura (C) (www.aatespanol.cl), o Vitruvio (http://vocabularyserver.com/vitruvio/)

También se recomienda incluir título, resumen y palabras clave en segundo idioma.

- La segunda página y siguientes deben tener en cuenta:

El cuerpo del artículo se divide en: Introducción, Metodología, Resultados y Discusión de resultados; posteriormente se presentan las Conclusiones, y luego las Referencias bibliográficas y los Anexos (modelo IMRYD). Las tablas y figuras se deben incorporar en el texto.

Descripción del proyecto de investigación: en la introducción se debe describir el tipo de artículo y brevemente el marco investigativo del cual es resultado y diligenciar el formato (RevArq FP02 Info Proyectos de Investigación).

TEXTO: todas las páginas deben venir numeradas y con el título de artículo en la parte superior de la página. Márgenes de $3 \mathrm{~cm}$ por todos los lados, interlineado doble, fuente Arial o Times New Roman de 12 puntos, texto justificado (Ver plantilla para presentación de artículos). La extensión de los artículos debe ser de alrededor de 5.000 palabras ( \pm 20 páginas, incluyendo gráficos, tablas, referencias, etc.); como mínimo 3.500 y máximo 8.000 palabras. Se debe seguir el estilo vigente y recomendado en el Manual para Publicación de la American Psychological Association (APA). (Para mayor información véase http://www.apastyle.org/)
Citas y notas al pie: las notas aclaratorias o notas al pie no deben exceder cinco líneas o 40 palabras, de lo contrario estas deben ser incorporadas al texto general. Las citas pueden ser:

Corta: (con menos de 40 palabras) se incorporan al texto y pueden ser: textuales (se encierran entre dobles comillas), parafraseo o resumen (se escriben en palabras del autor dentro del texto).

Cita textual extensa: (mayor de 40 palabras) debe ser dispuesta en un renglón y un bloque independiente con sangrías y omitiendo las comillas, no olvidar en ningún caso la referencia del autor (Apellido, año, página).

Referencias: como modelo para la construcción de referencias se emplea el estilo recomendado en el Manual para Publicación de la American Psychological Association (APA) (http://www.apastyle.org/).

Siglas: en caso de emplear siglas en el texto, las figuras o las tablas, se debe proporcionar la equivalencia completa la primera vez que se empleen y encerrarlas entre paréntesis. En el caso de citar personajes reconocidos se deben colocar nombres o apellidos completos, nunca emplear abreviaturas.

Figuras y tablas: las figuras (gráficos, diagramas, ilustraciones, planos, mapas o fotografías) y las tablas deben ir numeradas y contener título o leyenda explicativa relacionada con el tema del artículo, que no exceda las 15 palabras (Figura 1. xxxxx, Tabla 1. xxxx, etc.) y la procedencia (fuente: autor o fuente, año, página). Estas se deben referenciar en el texto de forma directa o entre paréntesis; se recomienda hacerlo con referencias cruzadas.

También se deben entregar en medio digital, independiente del texto, en formatos editables o abiertos. La marcación de los archivos debe corresponder a la incluida en el texto. Según la extensión del artículo se deben incluir de 5 a 10 gráficos. Ver guía para la búsqueda de imágenes de dominio público o bajo licencias Creative Commons (CC).

El autor es el responsable de adquirir los derechos o las autorizaciones de reproducción a que haya lugar para imágenes o gráficos tomados de otras fuentes, así como de entrevistas o material generado por colaboradores diferentes a los autores; de igual manera, se debe garantizar la protección de datos e identidades para los casos que sea necesario.

FotografíA: pueden ser entregadas en original para ser digitalizadas, de lo contrario se deben digitalizar con una resolución igual o superior a 300 dpi para imágenes a color y 600 para escala de grises. Los formatos de las imágenes pueden ser TIFF, PSD o JPG, y deben cumplir con las características expresadas en el punto anterior (figuras).

Planimetría: se debe entregar la planimetría original en medio digital, en lo posible en formato CAD, y sus respectivos archivos de plumas o en PDF; de no ser posible, se deben hacer impresiones en tamaño carta con las referencias de los espacios mediante numeración y lista adjunta. Deben tener escala gráfica, escala numérica, norte, coordenadas y localización. En lo posible, no deben contener textos, achurados o tramas.

Para más detalles, consultar el documento RevArq Parámetros para Autores Descripción en el portal web de la Revista de Arquitectura (Bogotá)

\section{Beneficios}

Como reconocimiento a los autores, se les hará envío postal de dos ejemplares de la edición impresa sin ningún costo y entregada en la dirección consignada en el formato de hoja de vida (RevArq FP01); adicionalmente, se enviará el vínculo para la descarga de la versión digital.

También se enviará una constancia informativa en la que se relaciona la publicación del artículo y, de manera opcional, se pueden detallar las fechas del proceso editorial y el arbitraje realizado. 
La selección de revisores se realiza de acuerdo con los siguientes criterios:

- Afinidad temática.

- Formación académica.

- Experiencia investigativa y profesional.

- Producción editorial en revistas similares o en libros resultado de investigación.

El proceso de arbitraje se basa en los principios de equidad e imparcialidad, y en los criterios de calidad y pertinencia.

El desarrollo de la revisión se realiza según el formato (RevArq FP10 Evaluación de artículos) y las observaciones que el revisor considere necesarias en el cuerpo del artículo. En cualquiera de los conceptos que emita el revisor (Aceptar, Publicable con modificaciones, Reevaluable o No publicable), y como parte de la labor formativa y de comunidad académica, el revisor hará sugerencias para mejorar et documento. El revisor podrá solicitar una nueva relectura del artículo después de los ajustes realizados por el autor.

El revisor también deberá diligenciar el formato RevArq FP01 Hoja de Vida, con el fin de certificar y soportar el proceso de revisión ante los SIR que así lo soliciten.

En el proceso de arbitraje se emplea el método doble ciego, los nombres del revisor no serán conocidos por el autor y viceversa. Con el fin de garantizar el anonimato del autor, al artículo postulado se le han podido suprimir nombres, instituciones o imágenes que puedan ser asociadas de manera directa al autor.

Aunque se procura el anonimato, una vez recibida la invitación como par revisor del artículo, el revisor debe cerciorarse de que no exista conflicto de intereses (CDI) o alguna limitante que afecte la revisión o que pueda ser vista como tal (lazos familiares, amistad o enemistad, vínculos contractuales o laborales, posiciones éticas, etc.), de presentarse esta situación se notificara al editor. (Ver modelo RevArq FP06 CDI).

Dada la confidencialidad del proceso de revisión, y considerando los derechos de autor y de propiedad intelectual que pueda haber sobre el material que se entrega, el revisor se compromete a mantener en absoluta reserva su labor, a limitar el uso de la obra entregada solo para el propósito designado y a devolver la documentación remitida una vez concluya la actividad.

El tiempo establecido para las revisiones de pares es de máximo un mes a partir de la confirmación de la recepción de la documentación. Ese plazo podrá ser modificado de mutuo acuerdo entre e editor y el revisor, siempre y cuando no afecte la periodicidad de la revista, la impresión o el tiempo para emitir una respuesta al autor.

Los revisores se acogerán a "COPE Ethical Guidelines for Peer Reviewers" de COPE.

\section{Beneficios}

Como retribución a los revisores se les hará envío postal de un ejemplar de la edición impresa sin ningún costo y entregada en la dirección consignada en el formato de hoja de vida. También, si es de interés para el revisor, podrá hacer la solicitud de alguna de las publicaciones editadas y presentes en el catálogo de publicaciones de la UNIVERSIDAD CATÓLICA DE COLOMBIA, previa aprobación de la Editorial y sujeto a la disponibilidad.

Si lo desea tendrá derecho a una constancia de la colaboración en la revisión de artículos, la cual solo contendrá el periodo en el cual se realizó la actividad. También tendrá la posibilidad de aceptar o no la publicación de su nombre, nacionalidad y nivel máximo de formación en la página web de la Revista de Arquitectura (Bogotá) en su calidad de colaborador.

\section{A Proceso de revisión por pares}

Luego de la postulación del artículo, el editor de la Revista de Arquitectura (Bogotá) selecciona y clasifica los artículos que cumplen con los requisitos establecidos en las directrices para los autores. El editor podrá rechazar en primera instancia artículos, sin recurrir a un proceso de revisión, si los considera de baja calidad o por presentar evidencias de faltas éticas o documentación incompleta.

Los artículos se someterán a un primer dictamen del editor, de los editores de sección y del Comité Editorial, teniendo en cuenta:

- Afinidad temática, relevancia del tema y correspondencia con las secciones definidas.

- Respaldo investigativo.

- Coherencia en el desarrollo del artículo, así como una correcta redacción y ortografía.

- Relación entre las figuras y tablas con el texto del artículo.
En esta revisión se verificará el nivel de originalidad mediante el uso de software especializado (Ithenticate o similar) y recursos digitales existentes para tal fin, también se observará la coherencia y claridad en los apartados del documento (modelo IMRYD), la calidad de las fuentes y la adecuada citación, esto quedará consignado en el formato (RevArq FP09 Revisión de artículos); esta información será cargada a la plataforma de gestión editorial y estará a disposición del autor.

En caso de que el artículo requiera ajustes preliminares, será devuelto al autor antes de ser remitido a revisores. En este caso, el autor tendrá veinte días para remitir nuevamente el texto con los ajustes solicitados.

Después de la preselección se asignan mínimo dos revisores especializados, quienes emitirán su concepto utilizando el formato (RevArq FP10 Evaluación de artículos) y las anotaciones que consideren oportunas en el texto; en esta etapa se garantizará la confidencialidad y el anonimato de autores y revisores (modalidad doble ciego).

Del proceso de revisión se emite uno de los siguientes conceptos que será reportado al autor:

\section{- Aceptar el envío: con o sin observaciones.}

- Publicable con modificaciones: se podrá sugerir la forma más adecuada para una nueva presentación, el autor puede o no aceptar las observaciones según sus argumentos. Si las acepta, cuenta con quince días para realizar los ajustes pertinentes.

- Reevaluable: cumple con algunos criterios y debe ser corregido. Es necesario hacer modificaciones puntuales y estructurales al artículo. En este caso, el revisor puede aceptar o rechazar hacer una nueva lectura del artículo luego de ajustado.

- No publicable: el autor puede volver a postular el artículo e iniciar nuevamente el proceso de arbitraje, siempre y cuando se evidencien los ajustes correspondientes.

En el caso de presentarse diferencias sustanciales y contradictorias en los conceptos sobre la recomendación del revisor, el editor remitirá el artículo a un revisor más o a un miembro del Comité Editorial quien podrá actuar como tercer árbitro, con el fin de tomar una decisión editorial sobre la publicación del artículo.

Los autores deberán considerar las observaciones de los revisores o de los editores, y cada corrección incorporada u omitida debe quedar justificada en el texto o en una comunicación adjunta. En el caso que los autores omitan las indicaciones realizadas sin una argumentación adecuada, el artículo será devuelto y no se dará por recibido hasta que no exista claridad al respecto.

El editor respetará la independencia intelectual de los autores y a estos se les brindará el derecho de réplica en caso de que los artículos hayan sido evaluados negativamente y rechazados.

Los autores, con su usuario y contraseña, podrán ingresar a la plataforma de Gestión Editorial, donde encontrarán los conceptos emitidos y la decisición sobre el artículo.

El editor y el Comité Editorial se reservan el derecho de aceptar o no la publicación del material recibido. También se reservan el derecho de sugerir modificaciones de forma, ajustar las palabras clave o el resumen y de realizar la corrección de estilo. El autor conocerá la versión final del texto antes de la publicación oficial del mismo.

Cuando un artículo es aceptado para su publicación, el autor debe firmar la autorización de reproducción (RevArq FP03 Autorización reproducción). Para más información ver: Política de derechos de autor

\section{Notas aclaratorias:}

La Revista de Arquitectura (Bogotá) busca el equilibrio entre las secciones, motivo por el cual, aunque un artículo sea aceptado o continúe en proceso de revisión, podrá quedar aplazado para ser publicado en un próximo número; en este caso, el autor estará en la posibilidad de retirar la postulación del artículo o de incluirlo en el banco de artículos del próximo número.

El editor y los editores de sección de la Revista de Arquitectura (Bogotá) son los encargados de establecer contacto entre los autores y revisores, ya que estos procesos se realizan de manera anónima.
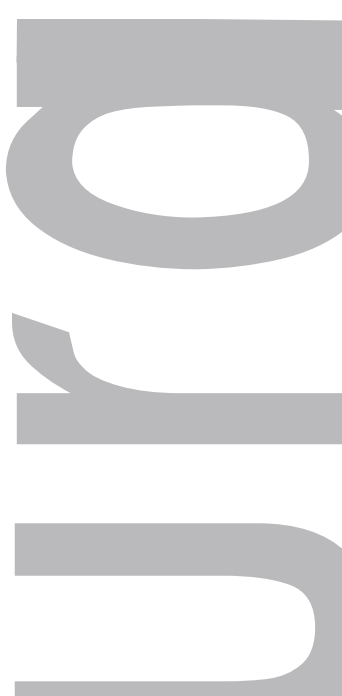
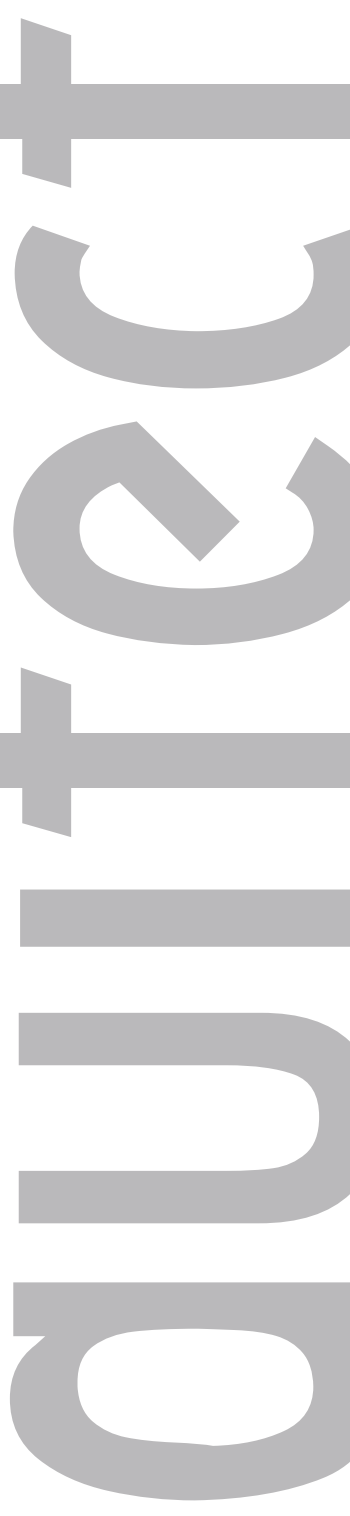

Vol. 


\section{Índice de caminabilidad para la ciudad de Bogotá \\ $\infty \quad$ Walkability index for the city of Bogotá \\ ن Índice de caminhabilidade para a cidade de Bogotá \\ Julián Alberto Gutiérrez-López \\ Yolanda Beatriz Caballero-Pérez
Rubén Alejandro Escamilla-Triana}

Principios, criterios y propósitos de desarrollo sustentable para la $\bar{\Upsilon}$ redensificacion en contextos urbanos informales

Principles, criteria and purposes of sustainable development for

re-densification in unplanned urban context

Princípios, critérios e propósitos de desenvolvimento sustent

Fabián Adolfo Aguilera-Martínez

Fabián Alonso Sarmiento-Valdés

Complejidad y constructivismo en la nueva tradición de la arquitectura de la posguerra

Complexity and constructivism in the new tradition of post-war architecture

U Complexidade e construtivismo na nova tradição da arquitetura do pósguerra

Francisco Javier Fuentes-Farías

Conservación del arte contemporáneo. El caso de Mathias Goeritz en la Catedral Metropolitana de México

Conservation of contemporary art: The case of Mathias Goeritz in the

$\varangle \quad$ Metropolitan Cathedral of Mexico

Conservação da arte contemporânea: o caso de Mathias Goeritz na Catedral Metropolitana do México

\section{Alberto Cedeño-Valdiviezo}

Pablo Torres-Lima

Operando desde la forma: un procedimiento para la valoración de la vivienda colectiva

On Operating based on form: A procedure for the valuation of collective housing

U Operando a partir da forma: um procedimento para avaliar a moradia coletiva

\section{Julián Camilo Valderrama-Vidal}

Disponibilidad de las técnicas constructivas de habitación en

ن Availability of timber housing construction techniques in Brazil

U. Disonibilidade das técnicas construtivas de moradia em madeira no Brasil

\section{Victor A. De Araujo}

Carlos M. Gutiérrez-Aguilar

Juliana Cortez-Barbosa

Maristela Gava

losé N. Garcia

Diseño y construcción de un paraguas plegable

Design and construction of a folding umbrella for architectural spaces

ن Desenho e construção de um guarda-chuva dobrável para espaços arquitetônicos

Carlos César Morales-Guzmán

Envolventes eficientes. Relación entre condiciones ambientales, espacios confortables y simulaciones digitales

(j) Efficient building envelopes: Relationship between environmental conditions,

U. comfortable spaces, and digital simulations

Envolventes eficientes: relação entre condições ambientais, espaços confortáveis e simulações digitais

Natalia Medina-Patrón

Jonathan Escobar-Saiz

(Re)pensando el enfoque tecnológico: el caso del Centro

Experimental de la Vivienda Económica (CEVE) en Argentina

ㅇ $(\mathrm{Re})$ thinking the technological approach: The case of the Experimental Center

으 for Economic Housing (CEVE) in Argentina

ن (Re)pensando a abordagem tecnológica. O caso do Centro Experimental da

Moradia Econômica na Argentina

Gustavo Pelegrin

Laila Fleker

Aurelio Ferrero 